Florida International University FIU Digital Commons

$11-15-2013$

\title{
Roles of DNA Base Excision Repair in Maintaining the Integrity of DNA Methylation
}

Jing Zhou

FIU,jzhou003@fiu.edu

DOI: $10.25148 /$ etd.FI13120903

Follow this and additional works at: https:// digitalcommons.fiu.edu/etd

Part of the Biochemistry, Biophysics, and Structural Biology Commons, and the Genetics and Genomics Commons

\section{Recommended Citation}

Zhou, Jing, "Roles of DNA Base Excision Repair in Maintaining the Integrity of DNA Methylation" (2013). FIU Electronic Theses and Dissertations. 1024.

https://digitalcommons.fiu.edu/etd/1024

This work is brought to you for free and open access by the University Graduate School at FIU Digital Commons. It has been accepted for inclusion in FIU Electronic Theses and Dissertations by an authorized administrator of FIU Digital Commons. For more information, please contact dcc@fiu.edu. 


\section{FLORIDA INTERNATIONAL UNIVERSITY}

Miami, Florida

\section{ROLES OF DNA BASE EXCISION REPAIR IN MAINTAINING THE INTERGRITY OF DNA METHYLATION}

A thesis submitted in partial fulfillment of the

requirements for the degree of

MASTER OF SCIENCE

in

CHEMISTRY

by

Jing Zhou

2013 
To: Dean Kenneth G. Furton

College of Arts and Sciences

This thesis, written by Jing Zhou, and entitled Roles of DNA base excision repair in maintaining the integrity of DNA methylation, having been approved in respect to style and intellectual content, is referred to you for judgment.

We have read this thesis and recommend that it be approved.

David Becker

Xiaotang Wang

Yuan Liu, Major Professor

Date of Defense: November 15, 2013

The thesis of Jing Zhou is approved.

Dean Kenneth G. Furton

College of Arts and Sciences

Dean Lakshmi N. Reddi

University Graduate School

Florida International University, 2013 
C Copyright 2013 by Jing Zhou

All rights reserved. 


\section{ACKNOWLEDGMENTS}

I would like to thank my graduate advisor and committee members and labmates who provided me with a variety of help during my graduate study.

Special thanks goes to my enthusiastic advisor, Dr. Yuan Liu. My career in biochemistry has been so exciting through working with her. I thank Dr. Liu wholeheartedly, not only for her excellent mentoring and tremendous support and training in her laboratory, but also for providing me with wonderful opportunities.

Profound gratitude goes to Dr. Xiaotang Wang and Dr. David Becker, who have been truly dedicated to mentoring my graduate training and career development. I am particularly indebted to Dr. Wang and Dr. Becker for their great support for everything during my training and career development.

I am very appreciated for the support from Dr. Samuel H. Wilson from National Institute of Environmental Health Sciences/National Institutes of Health providing me with purified base excision repair enzymes so generously and for his great support on my research.

I would also like to thank Meng $\mathrm{Xu}$, Yanhao Lai, Zhongliang Jiang and other labmates in the Liu laboratory for nurturing me the passion and enthusiasm for biochemistry, and for their great encouragement and help in every aspect of my research and life.

Finally, I would like to dedicate this thesis to my parents, Dangsheng Zhou and Yanmei Chai, for their tremendous support throughout my whole life and career development. 


\begin{abstract}
OF THE THESIS
ROLES OF DNA BASE EXCISION REPAIR IN MAINTAINING THE INTERGRITY

OF DNA METHYLATION
\end{abstract}

by

Jing Zhou

Florida International University, 2013

Miami, Florida

\title{
Professor Yuan Liu, Major Professor
}

DNA methylation and demethylation are involved in regulation of gene expression. $\mathrm{CpG}$ clusters have been identified as hotspots of oxidative damages and mutagenesis. DNA base excision repair can remove oxidative DNA damage on CpG clusters and mediate an active DNA demethylation pathway. In this study, we examined the molecular mechanisms underlying interactions among DNA methylation, demethylation and BER. Our results demonstrated that a single 5-methylcytosine did not exhibit a significant effect on BER. Surprisingly we found that the abasic site completely inhibited the activity of thymine DNA glycosylase (TDG) leading to the sustainment of the mismatch efficiently extended by pol $\beta$. Interestingly, APE1 3'-5' exonuclease could removed the mismatch. Our results demonstrate a molecular mechanisms underlying DNA base lesion and BER in maintenance of a normal DNA methylation pattern and a critical role of APE1 to combat pol $\beta$ extension of the mismatch thereby reducing the introduction of mutagenesis. 


\section{TABLE OF CONTENTS}

CHAPTER

PAGE

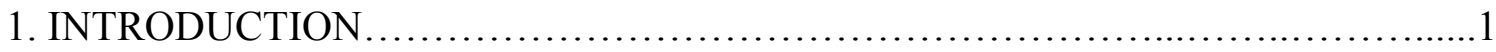

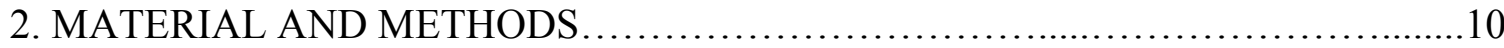

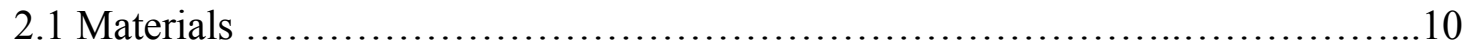

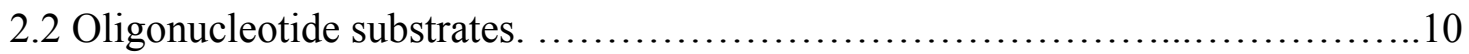

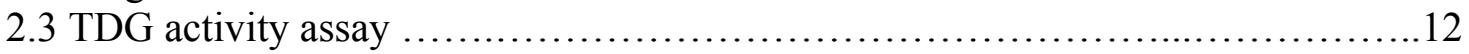

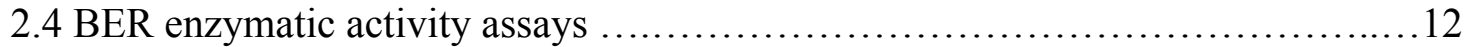

2.5 The efficiency of pol $\beta$ and APE1 activity

in the context of a $\mathrm{T} / \mathrm{G}$ mismatch ..............................................13

2.6 In vitro BER reconstitution with purified enzymes.............................13

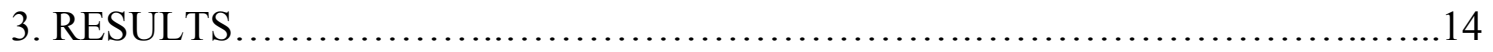

3.1 The effects of DNA methylation on base

excision repair

3.1.1 A $5 \mathrm{mC}$ does not exhibit a significant

effect on APE1 cleavage on the abasic site .................................14

3.1.2 A $5 \mathrm{mC}$ has no effect on pol $\beta$ DNA synthesis .....................................

3.1.3 Pol $\beta$ DNA synthesis is slightly stimulated

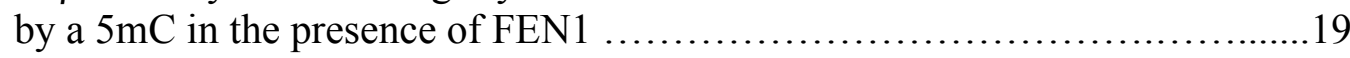

3.1.4. A $5 \mathrm{mC}$ does not affect on FEN1 cleavage

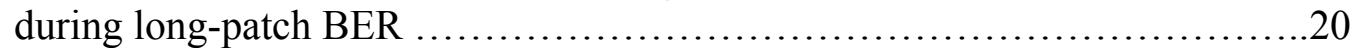

3.1.5 A 5mC does not affect DNA LIG I activity during BER ......................23

3.2 Interactions between DNA demethlyation

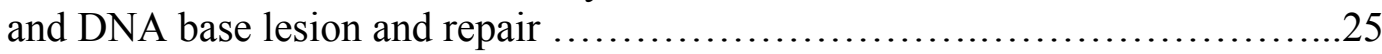

3.2.1 TDG efficiently removes the $\mathrm{T}$ from a $\mathrm{T} / \mathrm{G}$ mismatch ............................26

3.2.2 TDG is completely inhibited by an abasic lesion .............................28

3.2.3 APE1 activity is not affected by a 3'-mismatched T

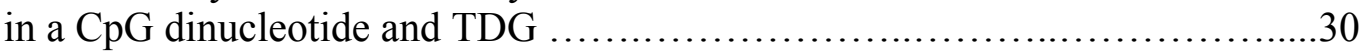

3.2.4 Pol $\beta$ can efficiently extend a 3'-mismatched $\mathrm{T}$................................. 31

3.2.5 APE1 3'-5' exonuclease activity efficiently

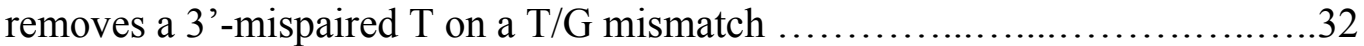

3.2.6 Removal of a 3'-mismatched nucleotide by APE1 3'-5' exonuclease activity

3.2.7 APE1 does not alter pol $\beta$ gap-filling synthesis for extending a 3'-terminus mismatched $\mathrm{T}$

3.2.8 The Klenow fragment of E. Coli DNA polymerase I can efficiently remove a 3'-mismatched $\mathrm{T}$

3.2.9 The efficiency of pol $\beta$ to extend a 3'-mismatched T and APE1 3'-5' exonuclease to remove a 3'-mismatched nucleotide. 
3.2.10 FEN1 failed to efficiently cleave a sugar

phosphate flap in the context of a $\mathrm{T} / \mathrm{G}$ mismatch ............................... 41

3.2.11 Base excision repair can occur

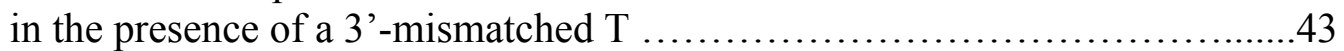

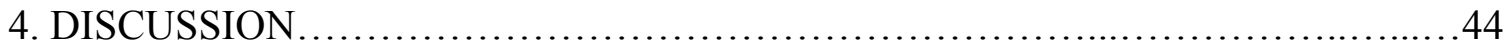

4.1 DNA methylation has no effect on BER …....................................44

4.2 Removal of a T/G mismatch generated by a DNA demethylation

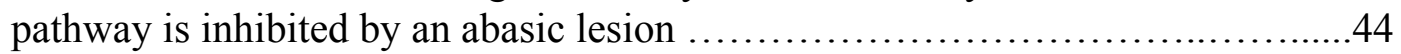

4.3. Tolerance of 3'-mismatched T by Pol $\beta$ and other DNA polymerases

4.4 APE1 3'-5' exonuclease removes a 3'-mismatched T and prevents pol $\beta$ extension of the mismatched nucleotide performing a proofreading function..

4.5 DNA demethylation on both strand of genes located on the $\mathrm{CpG}$ islands results in mutation that could not be corrected by BER

5. TABLE I OLIGONUCLEOTIDE SEQUENCE

6. REFERENCES. .50 


\section{LIST OF FIGURES}

FIGURE

PAGE

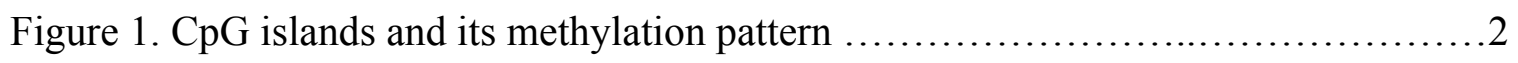

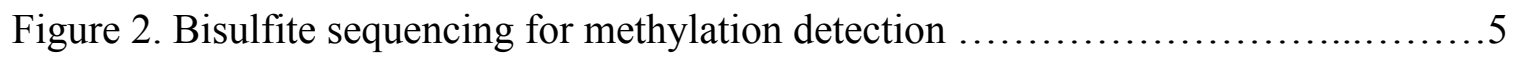

Figure 3. Base excision repair (BER) of oxidized DNA base lesion....................

Figure 4. DNA demethylation pathways .....................................

Figure 5. APE1 5'-incision activity on abasic site with a native or a modified sugar......15

Figure 6. APE1 5'-incision in the context of a complete DNA methylation .............16

Figure 7. Pol $\beta$ DNA synthesis in the context of DNA methylation during BER .......18

Figure 8. Pol $\beta$ DNA synthesis in the context of DNA methylation in HEPES buffer....18

Figure 9. Pol $\beta$ DNA synthesis in the context of DNA methylation in the presence of

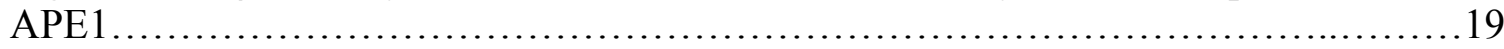

Figure 10. Pol $\beta$ DNA synthesis in the context of DNA methylation in the presence of FEN1.

Figure 11. FEN1 cleavage in the context of DNA methylation in the absence of pol $\beta$

Figure 12. FEN1 cleavage in the context of DNA methylation in the presence of pol $\beta$

Figure 13. DNA LIG I ligation in the context of DNA methylation .23

Figure 14. Reconstituted BER in the context of DNA methylation with a limited concentration of APE1 ..................................................... 24

Figure 15. Reconstituted BER in the context of DNA methylation with limited

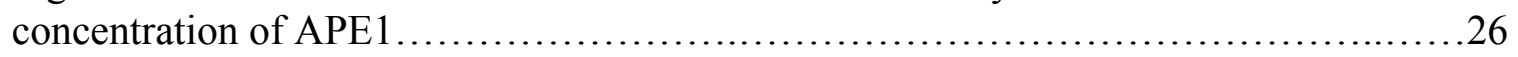

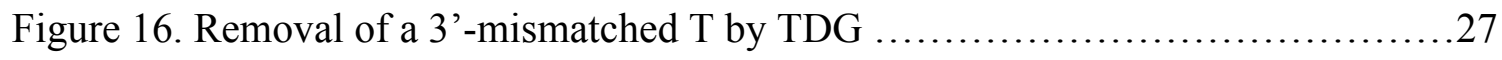

Figure 17. Removal of a 3'-mismatched T by TDG in the presence of APE1...........28

Figure 18. TDG activity is inhibited by an abasic base lesion.......................29

Figure 19. APE1 5'-incision of the abasic site in the presence of TDG................30 
Figure 20. Pol $\beta$ DNA synthesis in the context of a $T / G$ mismatch 31

Figure 21. Removal of a 3'-mimatched T by APE1 3'-5' exonuclease activity.... .33

Figure 22. Removal of a 3'-mismatched nucleotide at a nick by APE1 3'-5' exonuclease activity

Figure 23. Pol $\beta$ DNA synthesis in the presence of APE1 on substrates containing a T/G mismatch .....................................................................

Figure 24A. Wild type Klenow fragment's 3'-5' exonuclease activity....................38

Figure 24B. 3'-5' exo' mutant Klenow fragment's 3'-5' exonuclease activity ...........39

Figure 25A. Wild type Klenow fragment's DNA synthesis activity assay ..............39

Figure 25B. 3' -5 ' exo' mutant Klenow fragment's DNA synthesis activity assay ........40

Figure 26. Efficiency of APE1 3'-5' exonuclease and pol $\beta$ extension of a mismatched T

Figure 27. FEN1 cleavage in the context of a T/G mismatch in the absence of pol $\beta$

Figure 28. FEN1 cleavage in the context of a $\mathrm{T} / \mathrm{G}$ mismatch in the presence of pol $\beta$

Figure 29. Reconstituted BER in the context of a $\mathrm{T} / \mathrm{G}$ mismatch in the absence or presence of $50 \mathrm{nM}$ and $100 \mathrm{n}$ M APE1 


\section{LIST OF ABBREVIATIONS AND ACRONYMS}

Acronym

AID

AML

APE1

AP site

BER

DNMT

dRP

EVI1

FEN1

GSTP1

LIG I

MBD

$5 \mathrm{mC}$

MLL

8-oxoG

PAGE

PCNA

PNK

Pol $\beta$

ROS
Full Name

Active-induced DNA deaminase

Acute Myeloid Leukemia

AP endonuclease 1

Abasic Site

Base Excision Repair

DNA methyltransferase

5'-deoxyribose Phosphate

Ecotropic Viral Integration site

Flap endonuclease 1

Glutathione S-transferase pi

DNA ligase I

methyl-CpG Binding Domain

5-methylcytosine

Myeloid/Lymphoid or Mixed-Lineage

Leukemia

8-oxoguanine

Polyacrylamide gel electrophoresis

Proliferating Cell Nuclear Antigen

T4 Polynucleotide Kinase

DNA polymerase $\beta$

Reactive Oxygen Species 
SAM

SET

SETD1A

SMUG1

TDG

$T d T$

THF

TSG

UDG
S-Adenosylmethionine

$\mathrm{Su}(\mathrm{var}), \mathrm{E}(\mathrm{z})$ and Trithorax domain in Drosophila

SET domain containing $1 \mathrm{~A}$

Single-strand-selective monofunctional uracil-DNA glycosylase 1

Thymine DNA glycosylase

Terminal deoxynucleotidyl transferase

Tetrahydrofuran

Tumor Suppressor Gene

Uracil DNA glycosylase 


\section{Introduction}

DNA methylation is a covalent modification of a cytosine occurring on the 5 position of the DNA base that results in 5-methylcytosine $(5 \mathrm{mC})$ located on $\mathrm{CpG}$ dinucleotide motifs of the human genome [1-3]. In human somatic cells, 5-mC counts for $\sim 1 \%$ of total DNA base. But DNA methylation can affect up to $70 \%-80 \%$ of $\mathrm{CpG}$ dinucleotides in the human genome [3]. Methylated $\mathrm{CpG}$ islands is an important epigenetic marker, thus 5-methylcytosine is also called the fifth base of DNA [6]. DNA methylation is associated with repressive chromatin features that are mediated by methyl$\mathrm{CpG}$ binding proteins to affect the accessibility of transcription factors to the promoters and other regulatory regions of genes [7]. Moreover, methyl binding proteins also bind to domains that interact with histone modification enzymes such as histone methyltransferases as SET domain containing 1A (SETD1A) in Myeloid/Lymphoid, or Mixed-Lineage, Leukemia (MLL) indicating that DNA methylation can modulate histone modifications to activate or repress histones by inducing methylation of arginine or lysine residues, thus affecting the packaging of DNA to form chromatins and regulating gene functions [8-11].

CpG islands usually contain more than 200 base pairs with unmethylated and/or methylated CG-rich region containing high densities of $\mathrm{CpG}$ dinucleotides which are usually located on the 5 '-end of human gene promoter regions $[12,13]$. The majority of $\mathrm{CpG}$ islands are unmethylated at all stages of development and in all tissue types [1]. However DNA methylation that occurs on a small portion of the $\mathrm{CpG}$ islands plays a significant role. An unique DNA methylation pattern governs gene expression [14] and serves as an important epigenetic marker, that is relevant to gene imprinting, cell 
differentiation and development as well as the development of human cancer [15]. It has been proposed that hypermethylation of $\mathrm{CpG}$ islands leads to suppression of tumor suppressor gene (TSG) expression [12]. It was reported that DNA hypermethylation resulted in silencing of the retinoblastoma gene [16], therefore further resulted in the development of retinoblastoma [17]. Furthermore, hypermethylation in the promoter regions of the p16 and p53 gene can shut down expression of these genes leading to breast cancer and colon cancer, respectively [18]. In addition, hypermethylation at the promoters of the glutathione S-transferase pi (GSTP1) gene and the ecotropic viral integration site (EVI1) gene is involved in many other cancers such as prostate cancer and acute myeloid leukemia (AML) [19-22]. Interestingly, $\mathrm{CpG}$ islands in some oncogenes in tumor cells were found to be hypomethylated [15]. This resulted in activation of oncogene transcription and expression such as cMYC and H-RAS [23-25],

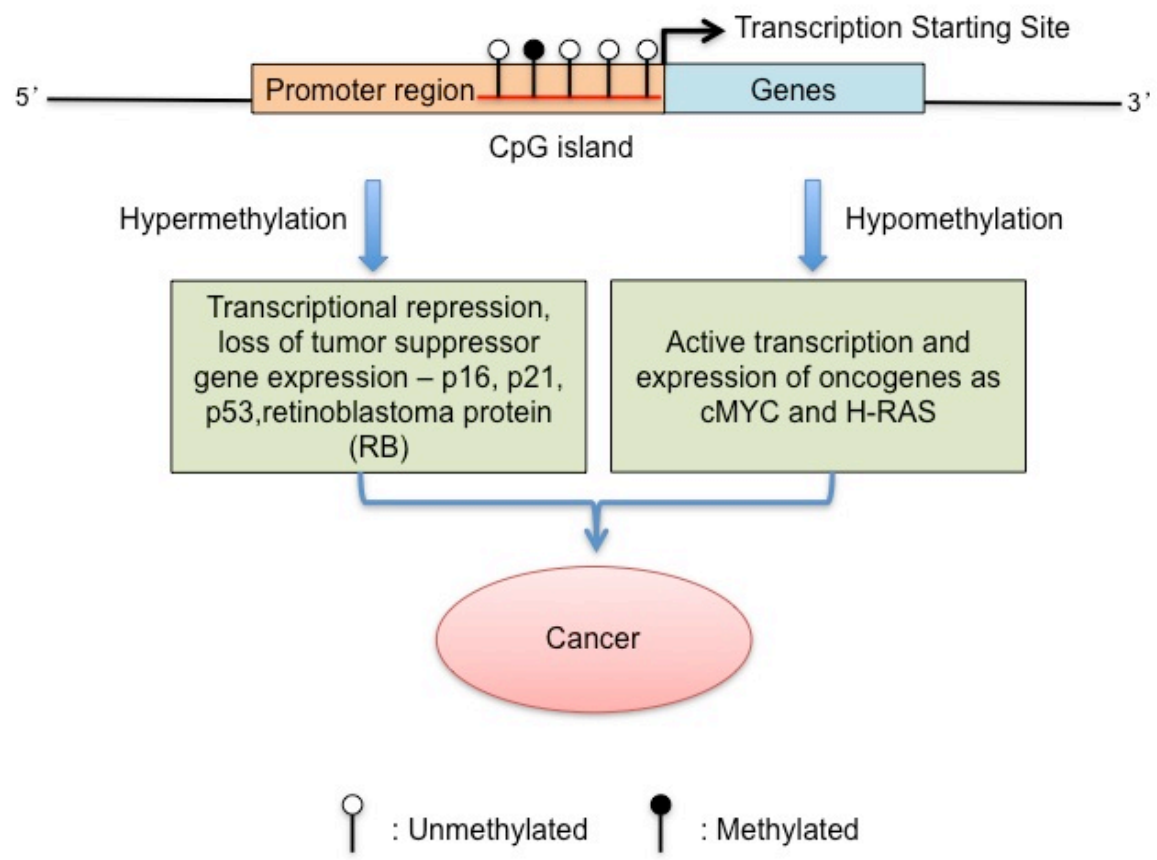

Figure 1. $\mathrm{CpG}$ islands and its methylation pattern 
and the activation of oncogene transcription and expression can further lead to metastatic hepatocellular cancer and cervical cancer [15]. Thus, DNA methylation on CpG islands is closely related to the development of human cancer [15] (Figure 1). In mammalian cells, DNA methylation is catalyzed by DNA methyltransferase (DNMT). A group of DNMTs, DNMT 3a and DNMT 3b can act as de novo DNMTs, which can methylate double strand DNA without any methyl groups, creating the initial pattern of DNA methylation in the human genome. Another member of the DNA methyltransferase family, DNMT1, acts as a maintenance DNA methyltransferase, which recognizes and methylates hemimethylated DNA with a 5-methylcytosine on one strand of DNA. Thus, DNMT1 is responsible for sustaining the original DNA methylation pattern in a newly synthesized DNA strand after DNA replication. DNMTs use S-Adenosylmethionine [26] as their cofactor and transfer the methyl group from SAM to C-5 of a cytosine [27].

Methylation of DNA can be measured by bisulfite sequencing, which involves two steps. In the first step, bisulfite is used to convert an unmethylated cytosine to uracil, whereas the methylated cytosine cannot react with bisulfite. In the second step, bisulfitetreated DNA fragments are amplified by PCR. During PCR, since uracil is produced from an unmethylated cytosine, it is base-paired with an adenine. This allows an unmethylated cytosine that is converted to a uracil eventually to be converted into thymine after two rounds of PCR amplification. In contrast, an intact methylated cytosine is still base-paired with a guanine and is maintained at the end of PCR amplification. PCR amplified DNA fragments from an unmethylated or methylated DNA template are then cloned into a cloning vector and sequenced for identifying the nucleotide alterations of the bisulfitetreated fragments. If conversion of a cytosine to a thymine is identified in an amplified 
fragment, this will indicate an unmethylated cytosine. In contrast, if conversion of a cytosine residue to guanine is identified, it will indicate that the cytosine is a 5methylcytosine (Figure 2)

Human DNA is under constant attack by exogenous and endogenous oxidative stress, that includes ultraviolet light, ionizing radiation, xenobiotic chemicals, and activated oxygen group carriers named reactive oxygen species (ROS) or activated methyl group carriers from metabolites in cell $[28,29]$. Although currently there is no accurate estimation about the absolute or relative amount of different types of DNA lesions caused by these factors, small deoxynucleotide lesions appear to be the most common type of damage [30]. Among different types of DNA damage, the most common form is oxidative DNA base lesion which is induced by ROS [31]. Multiple DNA repair mechanisms are required to remove DNA damage to sustain cell viability and prevent mutagenesis. Base excision repair (BER) of DNA is a mechanism that has evolved to primarily remove oxidative DNA base damage as well as other types of base lesions. Base excision repair is initiated through the removal of a damaged base by a DNA glycosylase that results in an abasic site. Subsequently, AP endonuclease 1 (APE1) incises the 5'-end of the abasic site leaving a one-nucleotide gap with a 5'-deoxyribose phosphate (dRP) residue. DNA polymerase $\beta$ (Pol $\beta$ ) removes the dRP group using its dRP lyase activity and fills in the gap using its polymerase activity creating a nicked DNA. In this scenario, only one nucleotide is replaced. Thus the APE1 and pol $\beta$ mediated pathway is called single-nucleotide BER (Figure 3)[5]. If a sugar is reduced or oxidized, it cannot be removed directly by Pol $\beta$ dRP lyase. Removal of the sugar phosphate is mediated through removal of one nucleotide attached to the sugar phosphate 
by flap endonuclease 1 (FEN1) [32] creating a nick is then sealed by DNA ligase I (LIG I) or DNA ligase III that generate a phosphoester bond linking the 3' hydroxyl group with the 5'-phosphate at the margin of the nick [28].

Many oxidative DNA base lesion hotspots have been identified in the human genome. Among them, $\mathrm{CpG}$ clusters are the typical example. Methylated and unmethylated $\mathrm{CpG}$ clusters can be attacked by oxidative DNA damaging agents, and this usually result in a series of DNA base lesions that include 5-

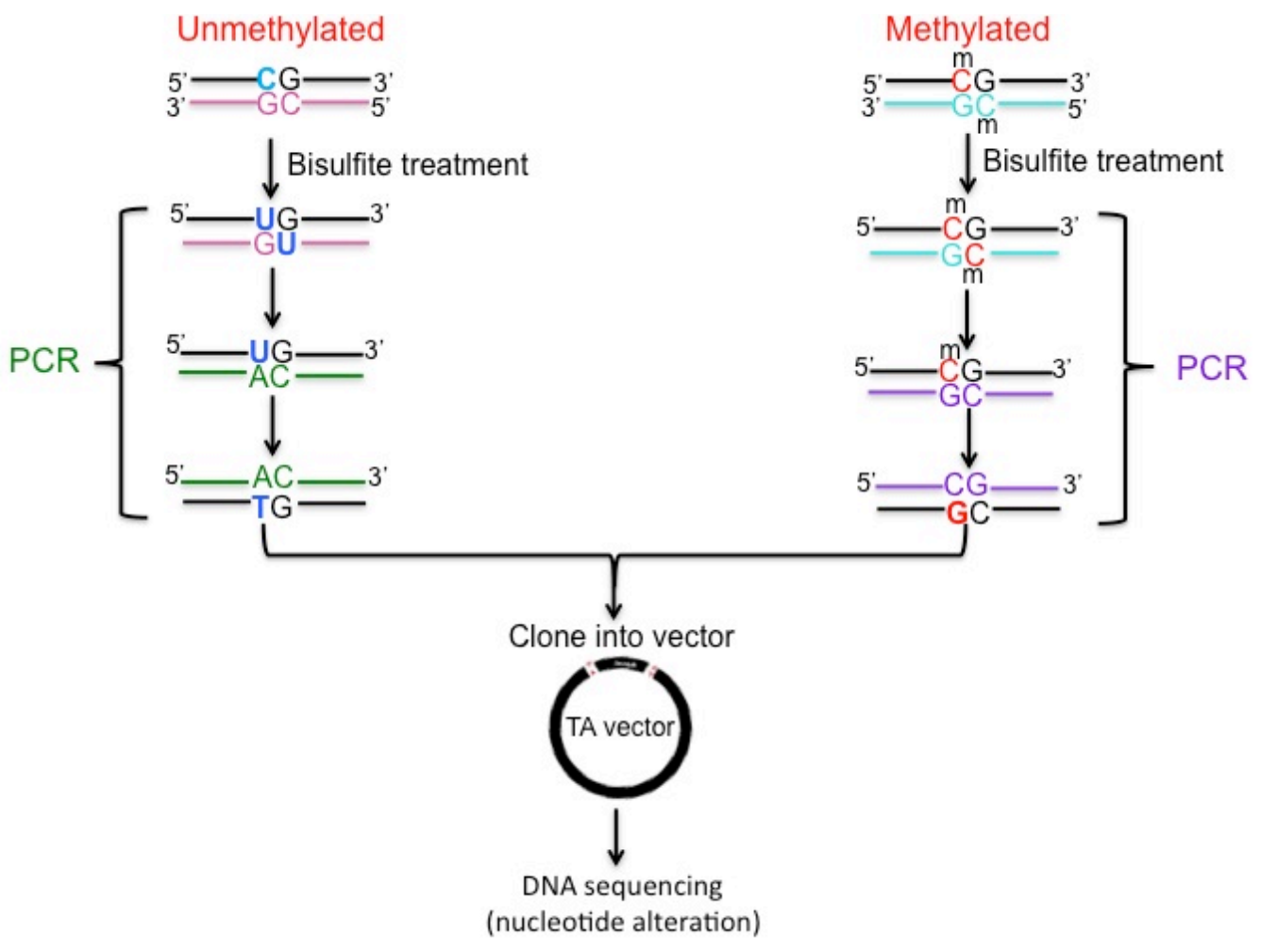

Figure 2. Bisulfite sequencing for methylation detection 


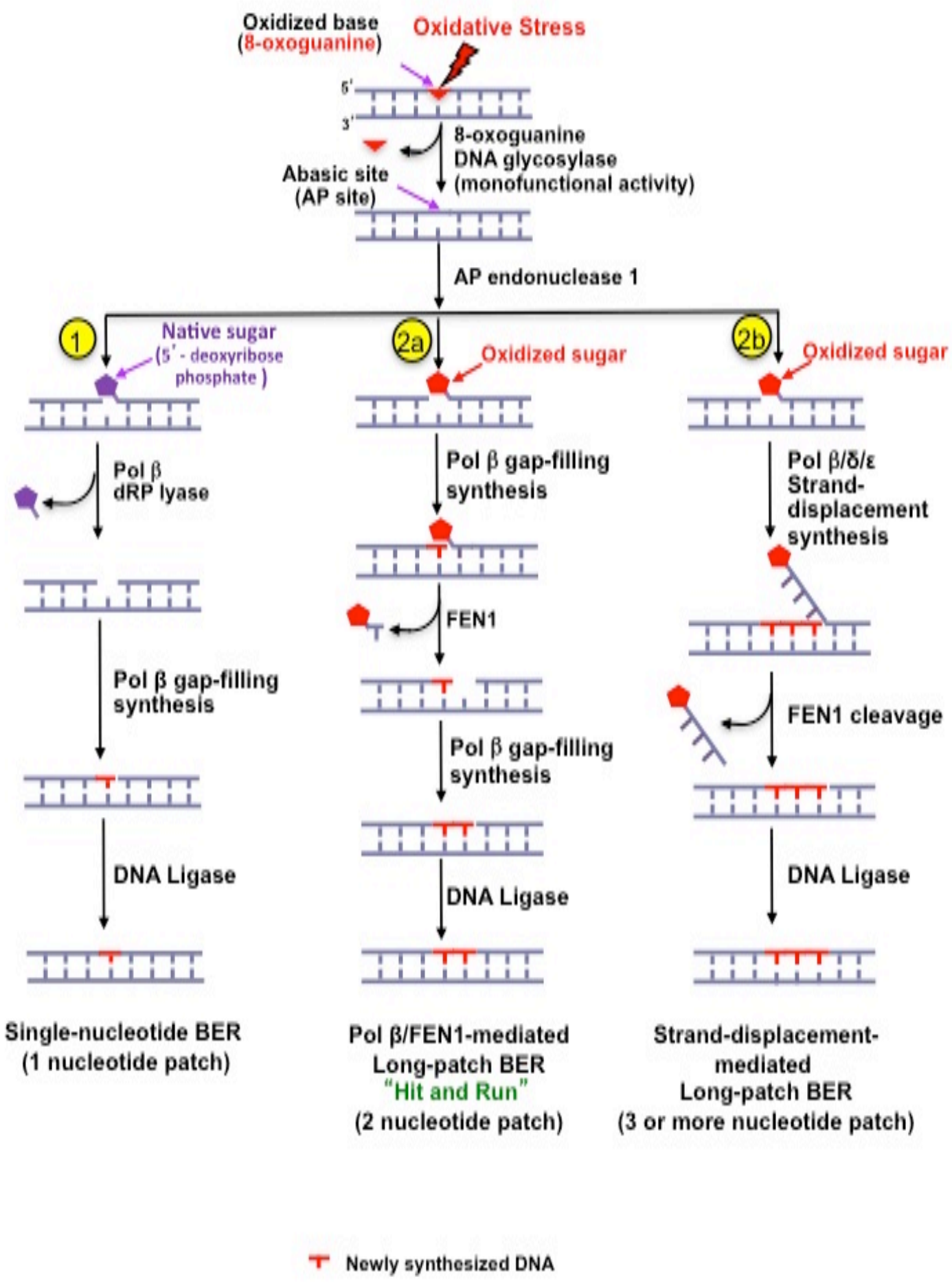

Figure 3. Base excision repair (BER) of oxidized DNA base lesions[5] 
hydroxymethylcytosine, 5-hydroxycytosine, 5,6-dihydroxycytosine, 8-oxoguanine and 8hydroxyguanine $[23,33,34]$. Recent studies have indicated that DNA base damage and repair have an important impact on DNA methylation. It has been found that 8oxoguanine (8-oxoG), the most abundant oxidative base lesion in DNA can further cause a mismatched base pair $[35,36]$, when it occurs adjacent to a $5 \mathrm{mC}$, it can inhibit methylCpG binding domain (MBD) binding to 5-mC thereby inhibiting DNA methylation [37]. In addition, free radicals generated from inflammation can result in 5-bromocytosine and 5-chlorocytosine that can mimic a $5 \mathrm{mC}$. It is conceivable that the size and hydrophobic properties of chlorine and bromine substituent may mimic the methyl group of 5methylcytosine and can be recognized by DNMT1 as a methyl group allowing a direct DNA methylation of target cytosine on the template strand DNA [11]. The methylated DNA can be subsequently bound by MBD inducing suppression of expression of a gene. Interestingly, cooperation among DNA methyltransferases, BER enzymes and cofactors has been implicated $[38,39]$. It has been found that DNMT $3 \mathrm{a}$ and $3 \mathrm{~b}$ can interact and stimulate thymine DNA glycosylase (TDG) activity [38, 39]. Furthermore, an in vivo study indicated that DNMT1 was recruited on DNA damaged sites along with a BER cofactor, proliferating cell nuclear antigen (PCNA) [40]. These results suggest that DNMTs can facilitate DNA base lesion repair.

A methlyated cytosine can be also removed by a process called DNA demethylation. DNA demethylation can occur either passively or actively. Passive DNA demethylation is the consequence of the failure of DNA methyltransferases to maintain DNA methylation pattern during cell division and DNA replication, whereas active DNA demethylation is mediated by sequential enzymatic reactions that occur in a large scale 
independent of cell division and DNA replication. Active DNA demethylation has emerged as a new hot research topic [4, 41-43]. Many studies have demonstrated that a series of enzymes are involved in removing a 5'-methylcytosine and replacing the methylated nucleotide with an unmethylated cytosine through a DNA repair process. Removal of a 5-methylcytosine involves several sequential steps that modify a 5methylcytosine. These include its hydroxylation, deamination, oxidation or combination of these steps $[4,16,44-57]$. Recent studies have indicated that BER is actively involved in DNA demethylation through several sub-pathways that depends on the type of DNA glycosylases $[4,58,59]$. One of important BER sub-pathways is initiated by a direct deamination of $5 \mathrm{mC}$ by activation-induced (cytidine) deaminase (AID) that converts $5 \mathrm{mC}$ to a thymine resulting in a $\mathrm{T} / \mathrm{G}$ mismatch [59], which can be subsequently removed by TDG. Removal of the T/G mismatch by TDG leads to subsequent BER steps that convert the $5 \mathrm{mC}$ into a unmethylated C. Another BER-mediated DNA demethylation pathway is initiated by single-strand-selective monofunctional uracil-DNA glycosylase 1 (SMUG1) that removes a 5 -formyluracil generated either from oxidation of a $5 \mathrm{mC}$ by a family of enzymes called Ten Eleven Translocation (TET) enzymes (Figure 4) [4, 16, 46, $47,49,50,55]$ or from oxidative DNA damage caused by hydroxyl radicals $[60,61]$. Thus, DNA base damage and BER is actively involved in both and passive and active DNA demethylation [62]. However, many questions remain to be answered as to if and how DNA base lesions may interfere DNA methylation and how these damages may be repaired in the context of DNA methylation by BER to restore a normal DNA methylation pattern, and if a DNA base lesion can affect DNA demethylation, and if DNA methylation can alter the efficiency of BER. To answer these questions, we 
initially characterized if DNA methylation has any effects on BER if a base lesion occurs on a $\mathrm{CpG}$ dinucleotide. We then characterized the effect of DNA methylation on BER efficiency and the effect of a DNA base lesion on an essential step of DNA demethylation .

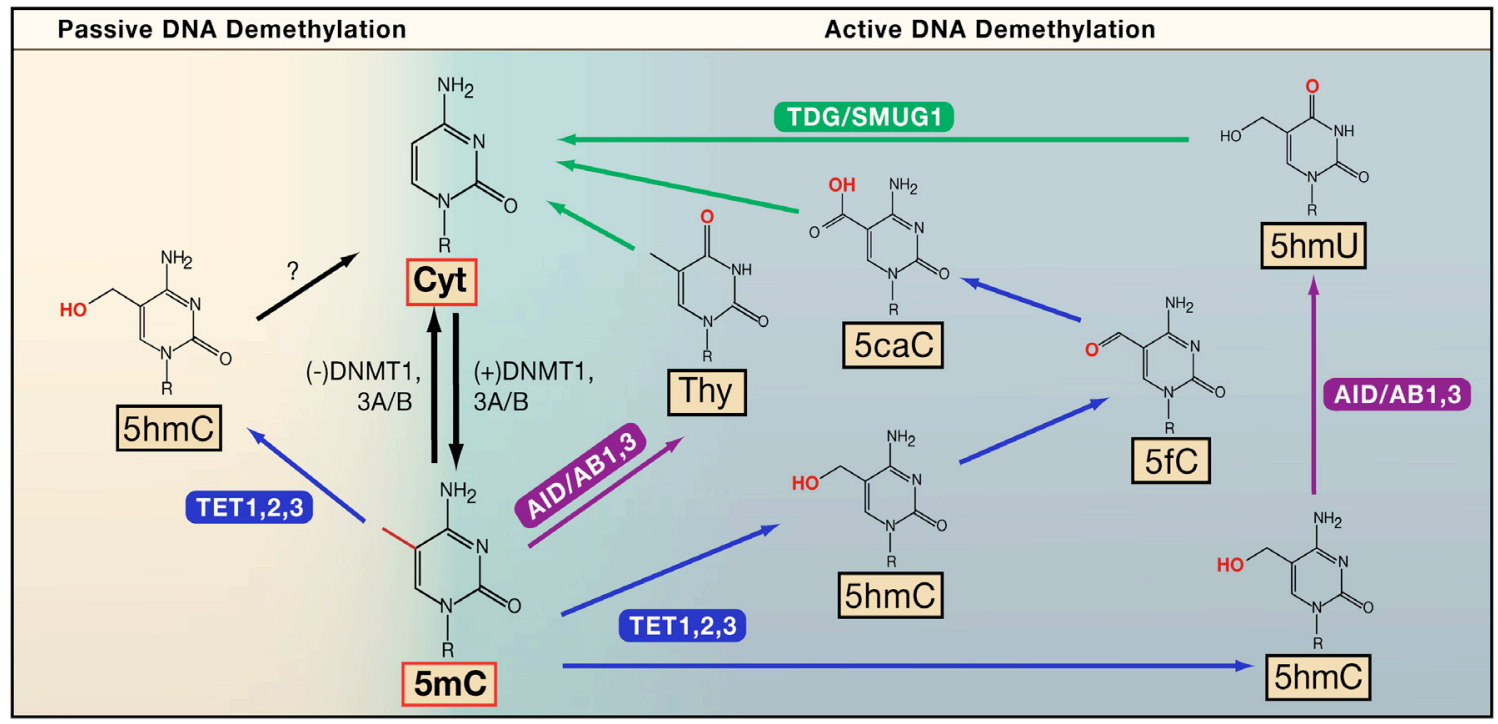

Figure 4. DNA demethylation pathways [4] 


\section{Material and methods}

2.1 Materials - DNA oligonucleotides containing a THF residue and a 5-methylcytosine or a $\mathrm{T} / \mathrm{G}$ mismatch were purchased from Integrated DNA Technologies Inc. (Coralville, IA). The radionucleotide $\left(\gamma^{-32} \mathrm{P}\right)$ ATP $(6000 \mathrm{Ci} / \mathrm{mmol})$, Deoxyadenosine 5 '-triphosphate $(6000 \mathrm{Ci} / \mathrm{mmol})$ and cordycepin $5^{\prime}$-triphosphate $3^{\prime}-\left(\alpha-{ }^{32} \mathrm{P}\right)(5000 \mathrm{mCi} / \mathrm{mmol})$ were obtained from Perkin Elmer (Boston, MA). Micro Bio-Spin 6 chromatography columns were obtained from Bio-rad (Hercules, CA). T4 polynucleotide kinase (PNK) and terminal deoxynucleotidyl transferase (TdT) were from Fermentas (Glen Burnie, MD). Adenosine 5'-triphosphate (ATP) (100 mM) was from USB (Cleveland, Ohio). AID and TDG were from Enzymax, LLC (Lexington, Kentucky). Purified uracil-DNA glycosylase (UDG), APE1, pol $\beta$, FEN1 and LIG I were generous gifts from Dr. Samuel H. Wilson at the Laboratory of Structural Biology, National Institute of Environmental Health Science/National Institutes of Health (NIEHS), Research Triangle Park, NC. All other reagents were from Thermo Fisher Scientific (Pittsburgh, PA) and Sigma-Aldrich (St. Louis, MO).

2.2 Oligonucleotide substrates - The DNA oligonucleotide substrates containing a 5methylcytosine and a tetrahydrofuran (THF), an abasic site analog were designed to mimic the products resulting from monofunctional OGG1 removal of 8-oxoG. In the present study, THF residue is used to represent an oxidized sugar phosphate. Substrates containing a nick were designed to mimic the product from removal of a flap by FEN1 cleavage. The BER substrates were prepared by annealing an oligonucleotide primer with a base lesion to its template strand at a molar ratio of 1:1.5 (template) or by annealing the upstream and downstream oligonucleotides to their template strand at a molar ratio of 
1:1.5 (template). The BER substrates were radiolabeled at the 5 '-end of the damagecontaining strand, and FEN1 substrates were radiolabeled at the 3'-end of the damagecontaining strand as indicated in Table I. The sequences of the oligonucleotides are listed in Table I. A DNA oligonucleotide substrate containing a T/G mismatched base pair or a $\mathrm{C} / \mathrm{G}$ matched base pair adjacent to a THF residue was designed to mimic the intermediates resulting from demethylation of a 5-methylcytosine by AID [4, 52] that is adjacent to an undamaged base or a base lesion, i.e., abasic site (AP site). The DNA oligonucleotide substrates containing a T/G mismatch at the upstream primer and a 5'THF residue at the downstream primer were designed to mimic the BER intermediates that contain an APE1-incised oxidized AP site that is adjacent to a T/G mismatched base pair and opposite to a template $\mathrm{C}$ or T. A control substrate contains an AP site adjacent to $\mathrm{C} / \mathrm{G}$ matched base pair and opposite to a template C. Substrates for measuring TDG activity were constructed by annealing a strand containing a mismatched $\mathrm{T} / \mathrm{G}$ base pair with its template strand at a molar ration of 1:1.5. Substrates for measuring BER enzymatic activity were constructed by annealing an upstream primer with a $3^{\prime}-\mathrm{T} / \mathrm{G}$ mismatched base pair and a downstream primer with a 5'-THF residue to its template strand at a molar ratio of 1:1:2. Substrates for measuring the activities of APE1, pol $\beta$, LIG I were radiolabeled at the 5'-end of the upstream strand, whereas substrates for measuring FEN1 cleavage were radiolabeled at the 3'-end of the downstream strand. The sequences of the oligonucleotides used are listed in Table I.

2.3 Thymine DNA glycosylase (TDG) activity assay - Thymine DNA glycosylase (TDG) activity for removing the $\mathrm{T}$ from a $\mathrm{T} / \mathrm{G}$ mismatch adjacent to a $\mathrm{THF}$ residue was examined at $37^{\circ} \mathrm{C}$ for $30 \mathrm{~min}$ in $10 \mu \mathrm{l}$ reaction buffer with $50 \mathrm{mM}$ Tris- $\mathrm{HCl}, \mathrm{pH}$ 7.5, 1 
mM EDTA, $1 \mathrm{mM}$ DTT, $0.1 \mathrm{mg} / \mathrm{ml} \mathrm{BSA,} \mathrm{0.01 \%} \mathrm{Nonidet} \mathrm{P-40).} \mathrm{Reactions} \mathrm{were}$ terminated by transferring the reaction mixture to $95^{\circ} \mathrm{C}$ for $5 \mathrm{~min}$. Reaction mixture was then treated with $0.1 \mathrm{M} \mathrm{NaOH}$ and denatured at $95{ }^{\circ} \mathrm{C}$ for $10 \mathrm{~min}$ in buffer containing $95 \%$ formamide and $10 \mathrm{mM}$ EDTA. Substrates and products were separated by $15 \%$ urea-denaturing polyacrylamide gel electrophoresis (PAGE) and detected by a Pharos FX Plus Molecules Imager (Bio-rad, Hercules, CA).

2.4 BER enzymatic activity assays - The AP endonuclease 1 (APE1) incision of the THF residue, an abasic site analog that is adjacent to 5-methylcytosine or a T/G mismatch, was measured at $37{ }^{\circ} \mathrm{C}$ in a $20-\mu \mathrm{l}$ reaction mixture containing $50 \mathrm{mM}$ Tris- $\mathrm{HCl}, \mathrm{pH} 7.50,50$ $\mathrm{mM} \mathrm{KCl}, 0.1 \mathrm{mM}$ EDTA, $0.1 \mathrm{mg} / \mathrm{ml}$ BSA, $5 \mathrm{mM} \mathrm{MgCl}_{2}, 50 \mu \mathrm{M}$ dNTPs, and $0.01 \%$ Nonidet P-40. Pol $\beta$ DNA synthesis on a single-nucleotide gapped substrate to extend a 3'-mismatched T or 3'-matched C was measured using a one-nucleotide gapped substrate containing a mismatched $\mathrm{T}$ or a matched $\mathrm{C}$ at the 3 '-terminus of the upstream primer that is adjacent to a THF residue at the downstream primer. The enzymatic reaction was performed by incubating $25 \mathrm{nM}$ substrates with various concentrations of pol $\beta$ at $37{ }^{\circ} \mathrm{C}$ for $15 \mathrm{~min}$ in a $10 \mu \mathrm{l}$ reaction mixture containing BER buffer $(50 \mathrm{mM}$ Tris- $\mathrm{HCl}, \mathrm{pH} 7.5$, $50 \mathrm{mM} \mathrm{KCl}, 0.1 \mathrm{mM}$ EDTA, $0.1 \mathrm{mg} / \mathrm{ml} \mathrm{BSA}, 0.01 \%$ Nonidet P-40, $5 \mathrm{mM} \mathrm{MgCl}_{2}$ ). AP endonuclease 1 (APE1) 3'-5' exonuclease activity for removing the $T$ from a $T / G$ mismatch was measured in BER buffer at $37{ }^{\circ} \mathrm{C}$ for $15 \mathrm{~min}$. FEN1 cleavage activity for removing the THF residue on the same substrate was examined in BER reaction buffer with $50 \mu \mathrm{M}$ dNTPs in the absence or presence of $5 \mathrm{nM}$ pol $\beta$ at $37{ }^{\circ} \mathrm{C}$ for $15 \mathrm{~min}$. Reactions were terminated by transferring to $95{ }^{\circ} \mathrm{C}$ for $5 \mathrm{~min}$ in a solution containing $95 \%$ 
formamide and $10 \mathrm{mM}$ EDTA. Substrates and products were separated by $15 \%$ ureadenaturing PAGE and detected by a Pharos FX Plus Molecules Imager.

2.5 The efficiency of pol $\beta$ and APE1 activity in the context of a T/G mismatch - The efficiency of pol $\beta$ gap-filling synthesis activity and APE1 3'-5' exonuclease activity was measured with $5 \mathrm{nM}$ pol $\beta$ and/or $50 \mathrm{nM}$ APE1 using $25 \mathrm{nM} 5{ }^{2}{ }_{-}^{32} \mathrm{P}$-labeled substrates. The reactions were performed with $5 \mathrm{nM}$ pol $\beta$ or $50 \mathrm{nM}$ APE1 in the absence or presence of pol $\beta$. Reaction mixture was assembled on ice and incubated at $37^{\circ} \mathrm{C}$ for 1,2 , 5, 10 and $15 \mathrm{~min}$, then terminated by transferring to $95^{\circ} \mathrm{C}$ for $5 \mathrm{~min}$ in stopping buffer containing $95 \%$ formamide and $10 \mathrm{mM}$ EDTA. DNA substrates and products were separated by $15 \%$ urea-denaturing PAGE and detected by a Pharos FX Plus Molecules Imager.

2.6 In vitro BER reconstitution with purified enzymes - Base excision repair (BER) in the context of a $5 \mathrm{mC}$ and $\mathrm{T} / \mathrm{G}$ mismatch was reconstituted with purified APE1, pol $\beta$, FEN1, LIG I and 1 nt-gapped substrate with a $5 \mathrm{mC}$ or $\mathrm{T} / \mathrm{G}$ mismatch on the upstream primer, and a THF residue on the downstream primer. The $10-\mu 1$ reaction mixture contained BER buffer with $50 \mu \mathrm{M}$ dNTPs, $2 \mathrm{mM}$ ATP, $5 \mathrm{mM} \mathrm{Mg}^{2+}$ and the indicated amounts of BER enzymes. Reaction mixture was assembled on ice and incubated at $37^{\circ} \mathrm{C}$ for $15 \mathrm{~min}$. Reactions were terminated by transferring to $95^{\circ} \mathrm{C}$ for $5 \mathrm{~min}$ in stopping buffer containing $95 \%$ formamide and $10 \mathrm{mM}$ EDTA. DNA substrates and products were separated by $15 \%$ urea-denaturing PAGE and detected by a Pharos FX Plus Molecules Imager. 


\section{RESULTS}

\subsection{The effects of DNA methylation on base excision repair.}

\subsubsection{A $5 m$ C does not exhibit a significant effect on APE1 cleavage on the abasic site.}

To examine whether DNA methylation may have any effects on in major BER enzymes such as APE1, Pol $\beta$, FEN1, LIG I, initially we examined APE1 5'-incision of both native and oxidized abasic site. Substrates containing 31 -nt with a $5 \mathrm{mC}$ adjacent to a 5 '-THF residue or a uracil were used to mimic BER intermediates with an abasic lesion that represents a native abasic site resulting from a DNA glycosylase or a modified abasic site resulting from ROS. An unmethylated substrate was used as a control (Figure 5). Experiments were initially performed using the hemimethylated substrates with a $5 \mathrm{mC}$ on damage strand (Figure 5, lanes 1-6 and 13-17). Enzymatic reactions were assembled on ice in buffer containing $0.1 \mathrm{nM}, 0.25 \mathrm{nM}, 0.5 \mathrm{nM}, 1 \mathrm{nM}$ APE1 and $5 \mathrm{mM} \mathrm{Mg}^{2+}$ in the presence and absence of $2.5 \mathrm{nM}$ UDG. The results showed that low concentration of APE1 at $0.25 \mathrm{nM}$ efficiently incised both a native and a modified abasic site, and there is no difference in its cleavage efficiency between substrates containing a 5-methylcytosine and unmethylated substrates. We then subsequently examined the effect of a $5 \mathrm{mC}$ on APE1 5'-incision of an abasic lesion when it is located at the template strand and opposite to the abasic site (Figure 6). We found that the $5 \mathrm{mC}$ did not significantly affect APE1 activity (Figure 6, lanes 1-6 and lanes 13-17). We then determined if a complete methylation of a $\mathrm{CpG}$ dinucleotide with a $5 \mathrm{mC}$ on the damaged strand and a $5 \mathrm{mC}$ on the template strand may alter APE1 activity during repair of an abasic site. The results showed that a complete methylation of $\mathrm{CpG}$ dinucleotides failed to influence APE1 
activity (Figure 6, lanes 6-10). These indicate that a methyl group does not exhibit any significant effect on APE1 5'-incision of a native or modified abasic site an abasic site.

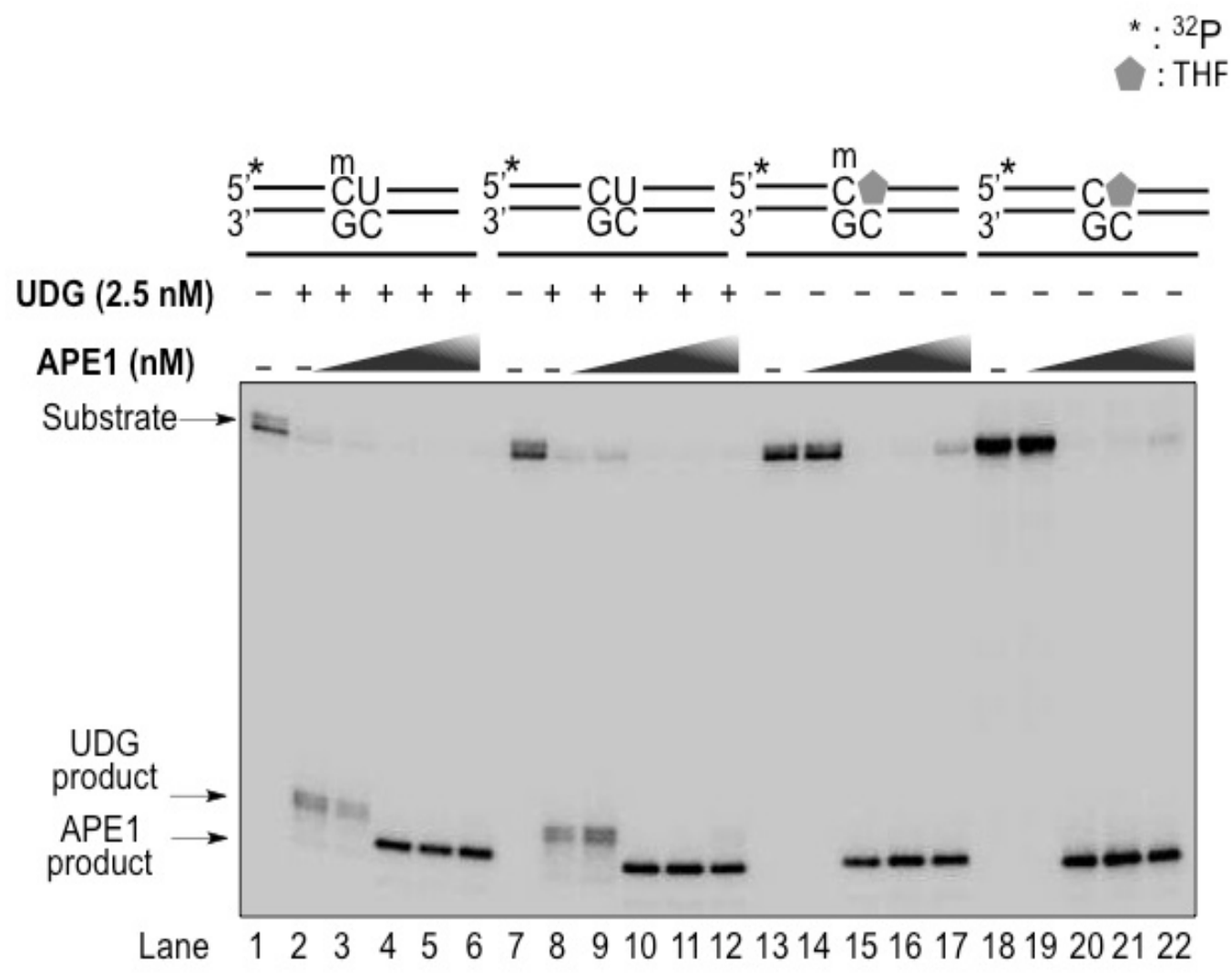

Figure 5. APE1 5'-incision activity on abasic site with a native or a modified sugar 


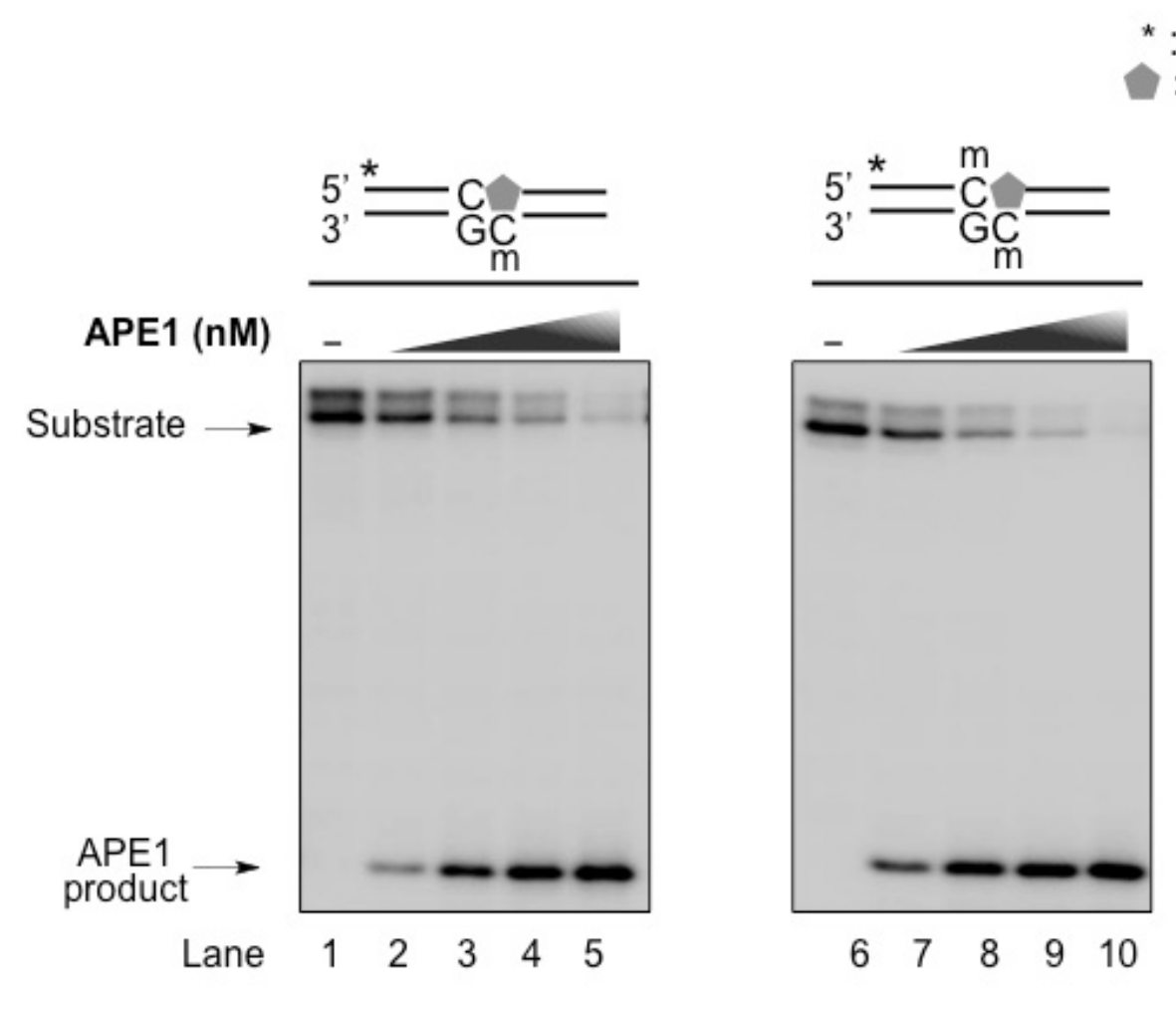

Figure 6. APE1 5'-incision in the context of a complete DNA methylation

3.1.2 A $5 \mathrm{mC}$ has no effect on pol $\beta$ DNA synthesis. We then examined the effects of a $5 \mathrm{mC}$ on pol $\beta$ gap-filling synthesis and strand displacement synthesis using substrates that contained a $5 \mathrm{mC}$ adjacent to a THF residue or uracil or two $5 \mathrm{mCs}$ located next to and opposite a base lesion (Figures 7,8 and 9). Experiments were conducted in presence of excessive amount of APE1 $(10 \mathrm{nM})$ and UDG $(2.5 \mathrm{nM})$ or the presence of APE1 alone to generate a 1 nt-gapped substrate for pol $\beta$ to perform gap-filling synthesis and strand displacement synthesis. The enzymatic activity was measured using $1 \mathrm{nM}, 2 \mathrm{nM}$ and 5 $\mathrm{nM}$ pol $\beta$ (Figure 7, lanes 4-6, 10-12, 15-17 and 20-22) with the substrates containing a uracil that further created a native abasic site or a THF residue. The results showed that for both of a native and modified abasic site, pol $\beta$ mainly inserted one nucleotide using 
its gap-filling synthesis activity (Figure 7 lanes 4, 10,15 and 20). However, no significant difference in pol $\beta$ gap-filling synthesis and strand displacement synthesis was detected between methylated substrates and unmethylated substrates (Figure 7 lanes 4-6, 10$12,15-17,20-22)$. To rule out the possibility that maybe pol $\beta$ was too active in Tris buffer used in our experimental conditions, and this diminished any effect of $5 \mathrm{mC}$ on pol $\beta$ DNA synthesis activity, we then examined pol $\beta$ gap-filling synthesis and strand displacement synthesis activities in HEPES buffer (Figure 8). The enzymatic activity was measured using $1 \mathrm{nM}, 2 \mathrm{nM}$ and $5 \mathrm{nM}$ pol $\beta$ (Figure 8, lanes 4-6, 10-12, 15-17 and 2022). Interestingly, in this buffer, pol $\beta$ exhibited a little bit of better DNA synthesis activity on substrates containing a THF than substrates with a native abasic site in the context of a $5 \mathrm{mC}$ (Figure 8, lanes 15-17 and 20-22). It was shown that even at a low concentration of pol $\beta$ at $1 \mathrm{nM}$, it inserted up to eight nucleotides or more. However, no significant difference shown in pol $\beta$ DNA synthesis between substrates containing $5 \mathrm{mC}$ and those containing an unmethylated cytosine. We then examined if a $5 \mathrm{mC}$ opposite an abasic lesion may affect the activity of pol $\beta$ DNA synthesis and found that a $5 \mathrm{mC}$ at this location did not affect pol $\beta$ DNA synthesis either (Figure 9, lanes 3-6). Finally, we determined if pol $\beta$ DNA synthesis could be affected by the presence of two $5 \mathrm{mCs}$ that are located adjacent to and opposite a base lesion. The results showed that the presence of both $5 \mathrm{mCs}$ did not exhibit a significant effect on pol $\beta$ DNA synthesis (Figure 9, lanes 912). Thus our results support a notion that DNA methylation does not affect pol $\beta$ gapfilling synthesis and strand displacement synthesis activity during both single-nucleotide 
and long-patch BER, and this is buffer condition independent.

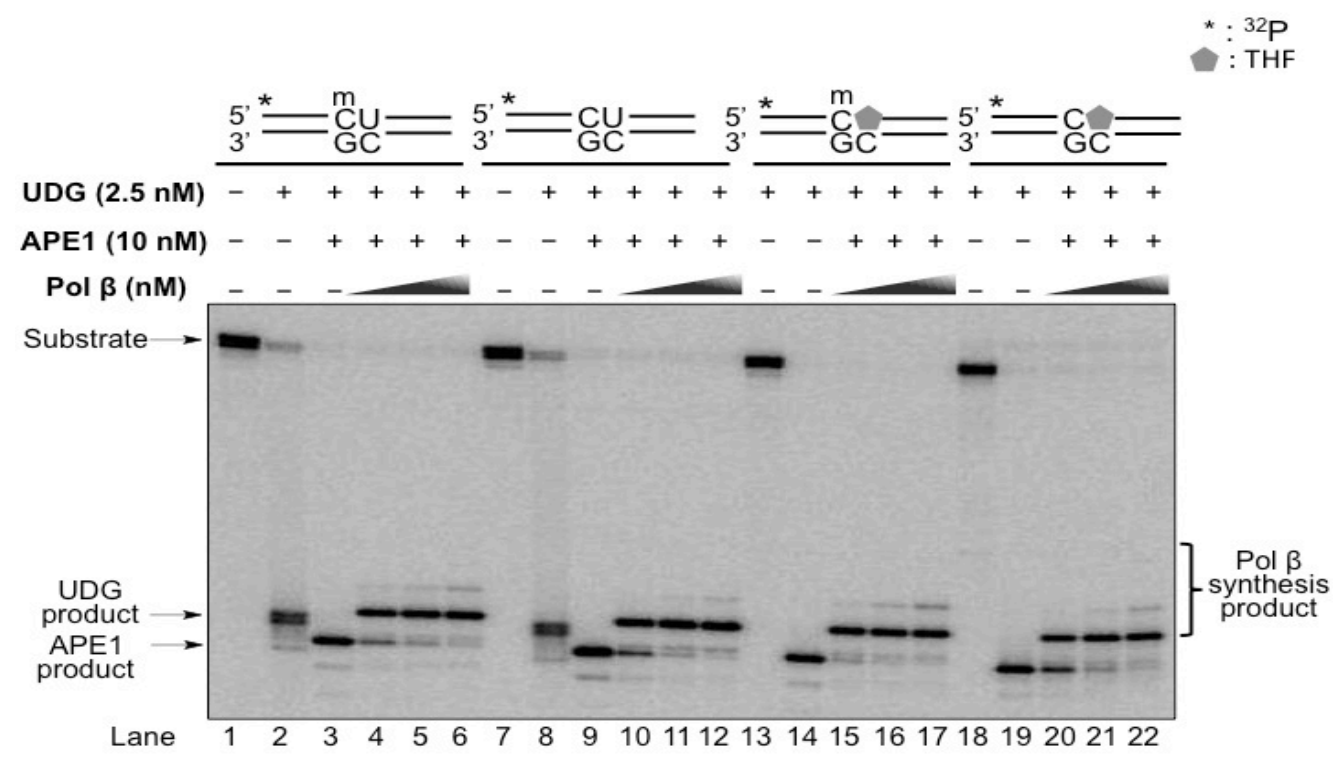

Figure 7. Pol $\beta$ DNA synthesis in the context of DNA methylation during BER

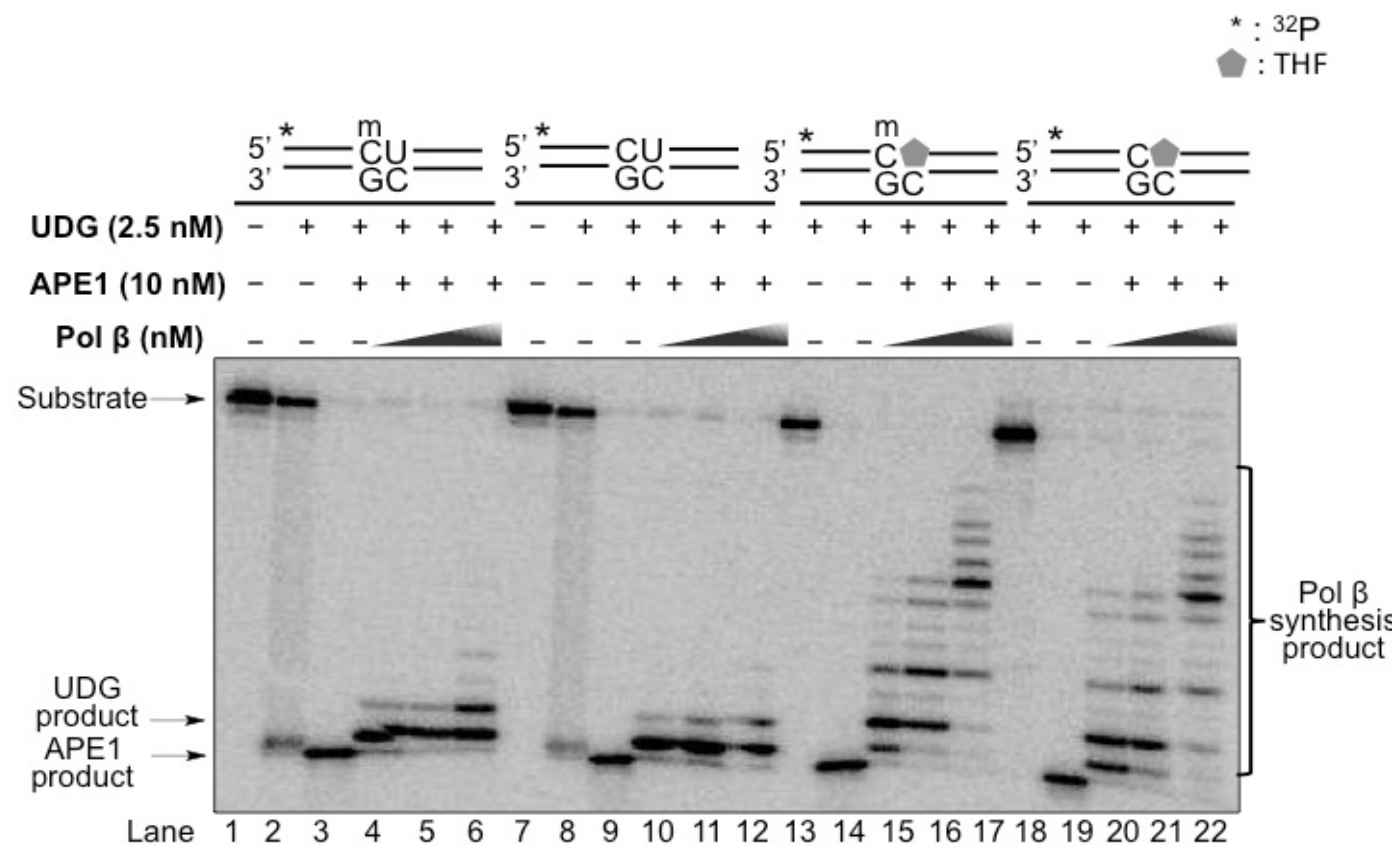

Figure 8. Pol $\beta$ DNA synthesis in the context of DNA methylation in HEPES buffer 


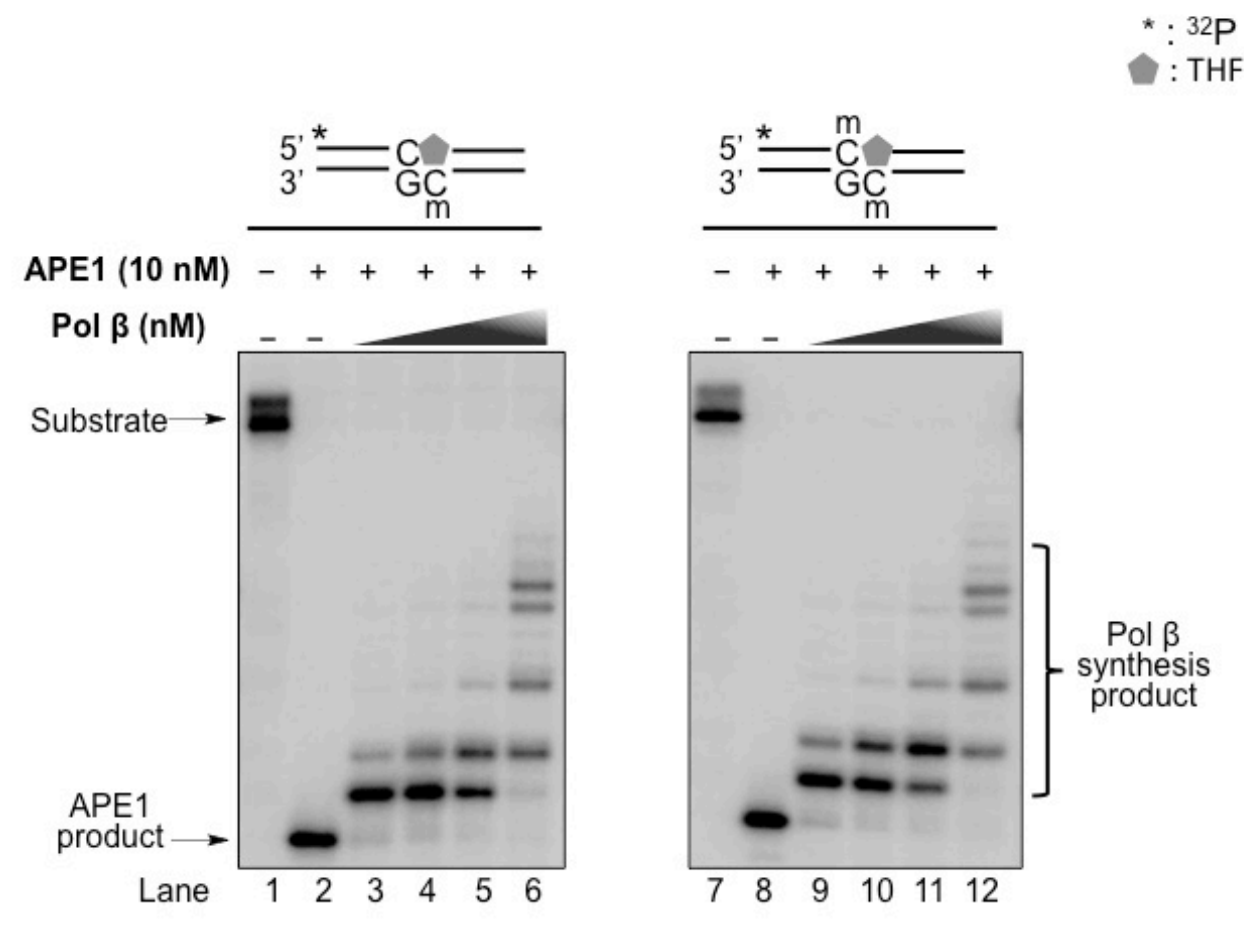

Figure 9. Pol $\beta$ DNA synthesis in the context of DNA methylation in the presence of APE1

\subsubsection{Pol $\beta$ DNA synthesis is slightly stimulated by a $5 \mathrm{mC}$ in the presence of FEN1.}

Since it has been reported that FEN1 and pol $\beta$ can coordinate with each other to mediate efficient long-patch BER $[32,63]$. We examined pol $\beta$ DNA synthesis in the presence of FEN1 to determine if a $5 \mathrm{mC}$ has any effect on FEN1-pol $\beta$ coordination. Experiments were conducted using a substrate containing a $5 \mathrm{mC}$ adjacent to an abasic lesion (Figure 10). Excessive amount of APE1 (10 nM) was used to precut an abasic site to ensure that all abasic sites were 5 '-incised. Pol $\beta$ activity was examined in the absence or the presence of increasing concentrations of FEN1 from $0.5 \mathrm{nM}$ to $10 \mathrm{nM}$ (Figure 10, lanes 3-6, 8-11, 14-17 and 19-22). For a substrate with a 5mC, pol $\beta$ exhibited better DNA 


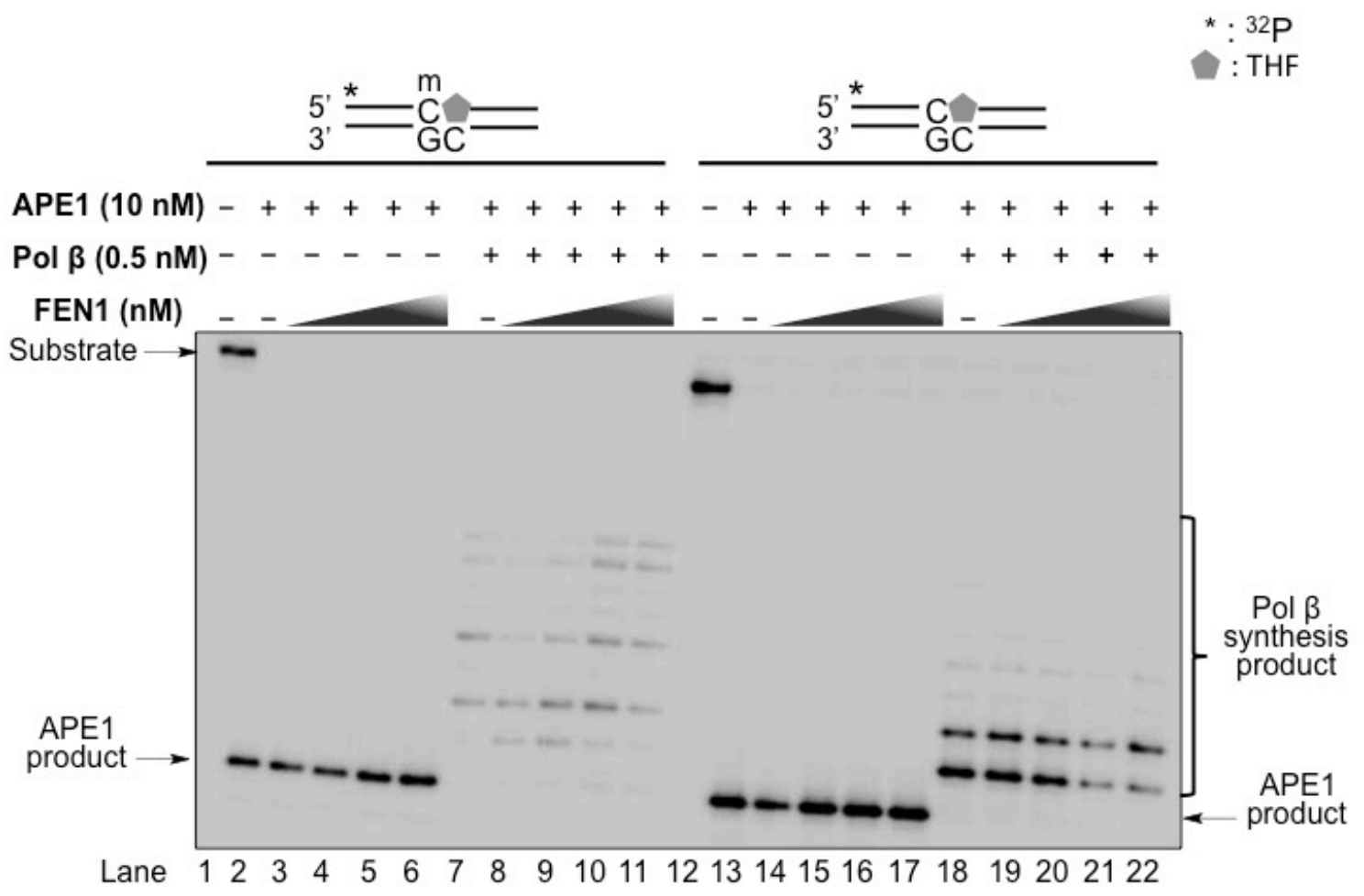

Figure 10. Pol $\beta$ DNA synthesis in the context of DNA methylation in the presence of FEN1

synthesis by inserting more nucleotides than it did with an unmethlyated substrate (Figure 10, lanes 8-11 and 19-22). The effect of pol $\beta$ synthesis is FEN1 independent (Figure 10, compare lane 7 with lanes $8-11$ ). The results indicate that a $5 \mathrm{mC}$ adjacent to an abasic site slightly stimulated pol $\beta$ DNA synthesis as well as facilitates pol $\beta$-FEN1 coordination during long-patch BER. 
3.1.4. A $5 m$ C does not affect on FEN1 cleavage during long-patch BER. To determine if a $5 \mathrm{mC}$ can affect FEN1 cleavage of a sugar phosphate during long-patch BER, we used substrates with a $5 \mathrm{mC}$ adjacent to a THF residue or with a $5 \mathrm{mC}$ opposite a THF residue or with two $5 \mathrm{mCs}$ both adjacent to and opposite an abasic site. Experiments were conducted using $3{ }^{3}-{ }^{32} \mathrm{P}$ labeled methylated substrates, and an unmethylated substrate used as a control (Figure 11 and 12). FEN1 flap cleavage activity was examined in the absence or the presence of $2 \mathrm{nM}$ pol $\beta$ with increasing concentrations of FEN1 ranging from 0.5 $\mathrm{nM}$ to $5 \mathrm{nM}$. In the absence of pol $\beta$, FEN1 exhibited a poorer cleavage activity only generating cleavage product at higher concentration at $5 \mathrm{nM}$ (Figure 11, lanes 4, 8, 12 and 16). In the presence of pol $\beta$, FEN1 cleavage activity was significantly increased, and more cleavage products were observed (Figure 12, lanes 4-6, 10-12, 16-18 and 22-24).

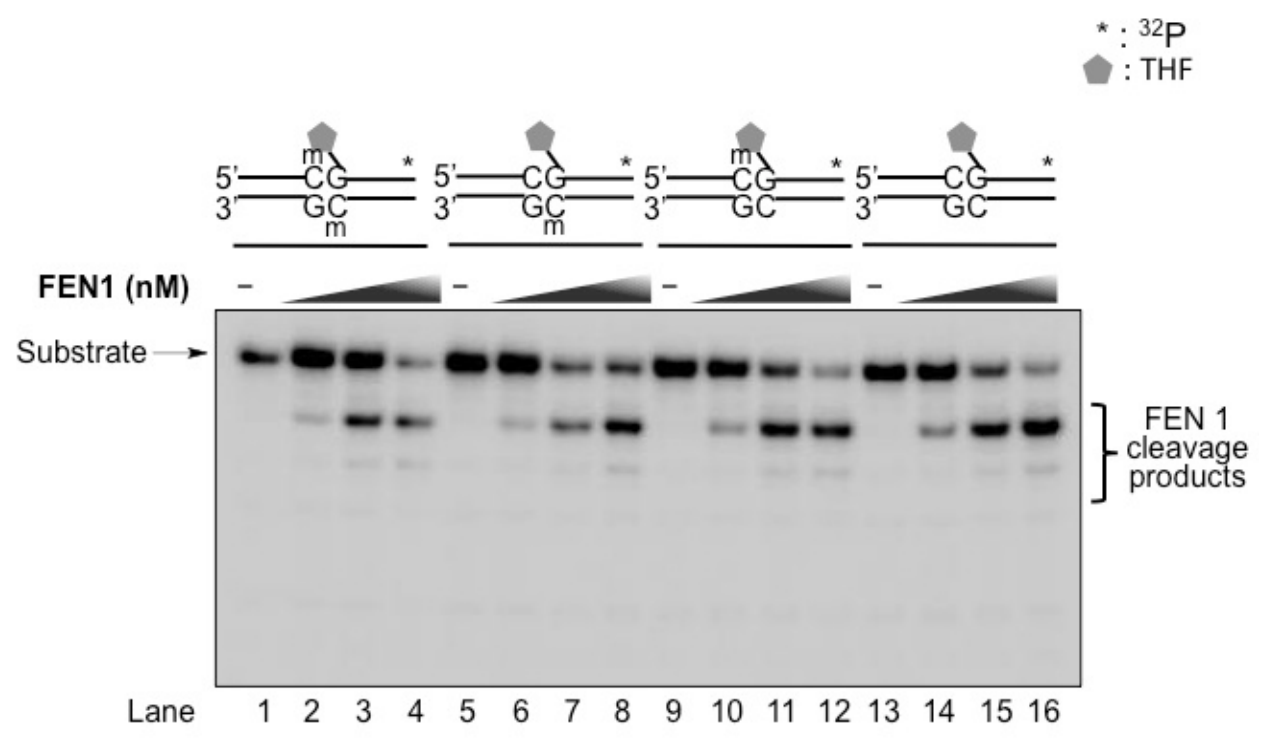

Figure 11. FEN1 cleavage in the context of DNA methylation in the absence of pol $\beta$ 
The presence of a $5 \mathrm{mC}$ adjacent to a THF did not exhibit any significant effect on FEN1 flap cleavage compared with the unmethylated substrate (Figure 12, lanes 4-6, 10-12, lanes 16-18 and 22-24) indicating that a 5mC next to an abasic site does not affect FEN1 cleavage. We further examined FEN1 cleavage on a substrate with a $5 \mathrm{mC}$ opposite to a THF residue. The experiment was conducted with increasing concentrations of FEN1 ranging from 0.5 to $5 \mathrm{nM}$ (Figure 12, lanes 10-12). The results showed that FEN1 cleavage of a THF residue opposite a $5 \mathrm{mC}$ did not exhibit a significant difference from it did with an unmethylated substrate indicating a $5 \mathrm{mC}$ failed to affect FEN1 cleavage of the THF residue by its flap cleavage activity (Figure 12, lanes 10-12). We then asked if two $5 \mathrm{mCs}$ located both next to and opposite an abasic site could have an effect on FEN1 cleavage. We examined the possibility using a substrate with two $5 \mathrm{mCs}$ located next to

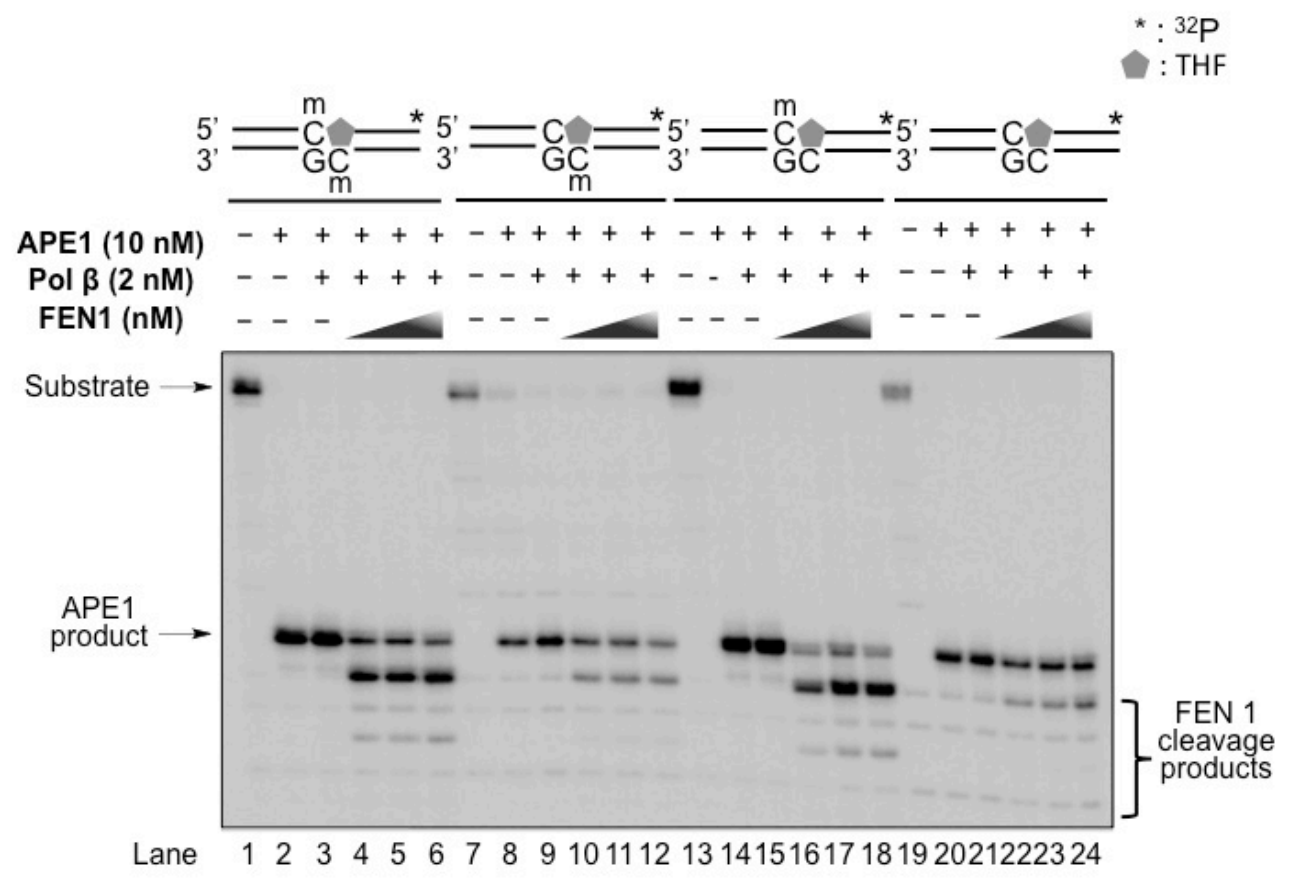

Figure 12. FEN1 cleavage in the context of DNA methylation in the presence of pol $\beta$ 
and opposite a THF residue (Figure 12, lanes 4-6). We found that FEN1 cleavage on this substrate did not show a significant difference from its cleavage on the unmethylated substrate. No difference indicates that FEN1 cleavage is not altered by a complete methylated $\mathrm{CpG}$ dinucleotide. Our results demonstrate that DNA methylation does not alter FEN1 flap cleavage activity during long-patch BER.

3.1.5 A $5 \mathrm{mC}$ does not affect DNA LIG I activity during BER. We then examined the effect of DNA methylation on the activity of LIG I in sealing a nick. A series of substrates containing a nick with a $5 \mathrm{mC}$ on different positions were used to mimic a nicked DNA that is adjacent to a $5 \mathrm{mC}$ or opposite to a $5 \mathrm{mC}$ or adjacent and opposite a $5 \mathrm{mC}$ simultaneously. The substrates were used to examine if a hemimethylated and complete methylated $\mathrm{CpG}$ dinucleotide can affect the ligation step of BER mediated by LIG I. The results demonstrated that no significant difference in ligation mediated by LIG I ranging from $1 \mathrm{nM}$ to $5 \mathrm{nM}$ was detected with all the substrates tested (Figure 13).

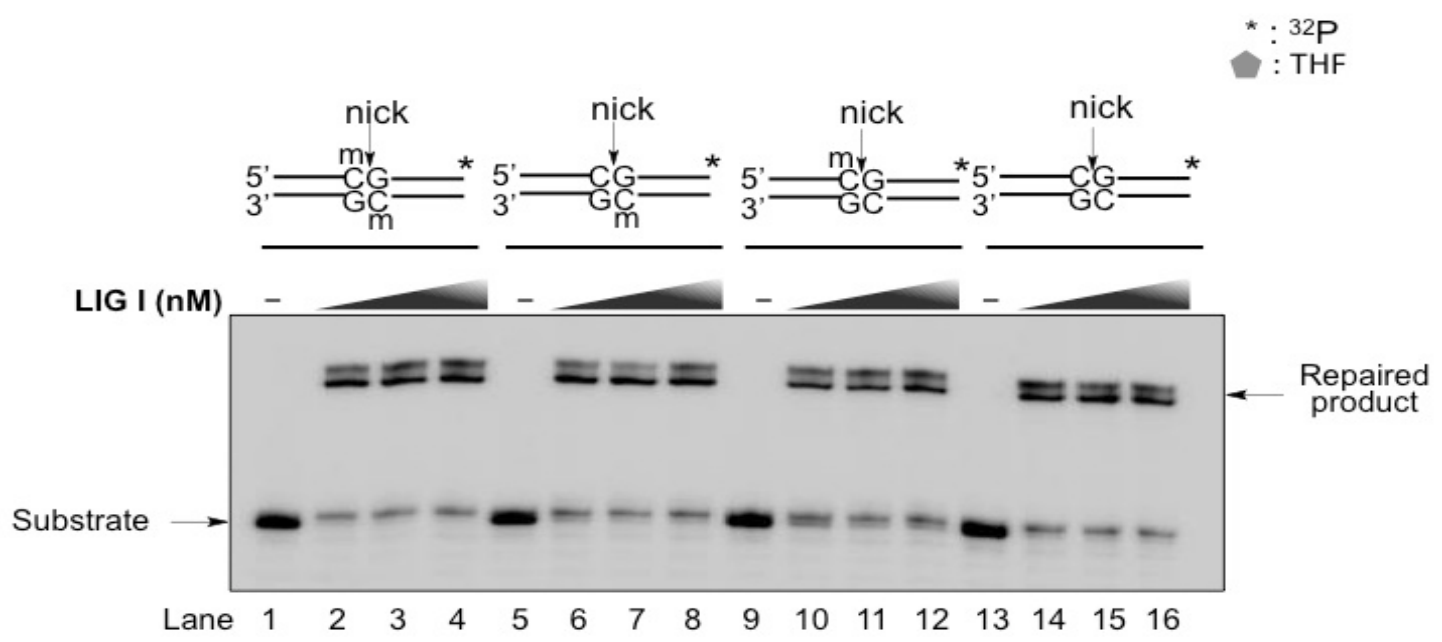

Figure 13. DNA LIG I ligation in the context of DNA methylation 
Therefore we concluded that DNA methylation does not influence the activity of LIG I for sealing nicked DNA.

3.1.6 DNA methylation does not affect BER efficiency. Since we identified a slight stimulatory effect of a $5 \mathrm{mC}$ on pol $\beta$ during long-patch BER, we wanted to examine whether the effect may influence total BER capacity through facilitating pol $\beta$-FEN1 coordination by conducting enzyme reconstitution experiments using a series of substrates containing a $5 \mathrm{mC}$ located at various positions related to a THF residue. The unmethylated substrate was used as a control. BER was reconstituted with purified APE1, Pol $\beta$, FEN1 and LIG I. Experiments were conducted firstly using a limited concentration of APE1 at $0.25 \mathrm{nM}$ and $2 \mathrm{nM}$ pol $\beta, 1 \mathrm{nM} \mathrm{FEN1}$ and $5 \mathrm{nM} \mathrm{LIG} \mathrm{I} \mathrm{to} \mathrm{determine} \mathrm{if} \mathrm{there} \mathrm{is}$

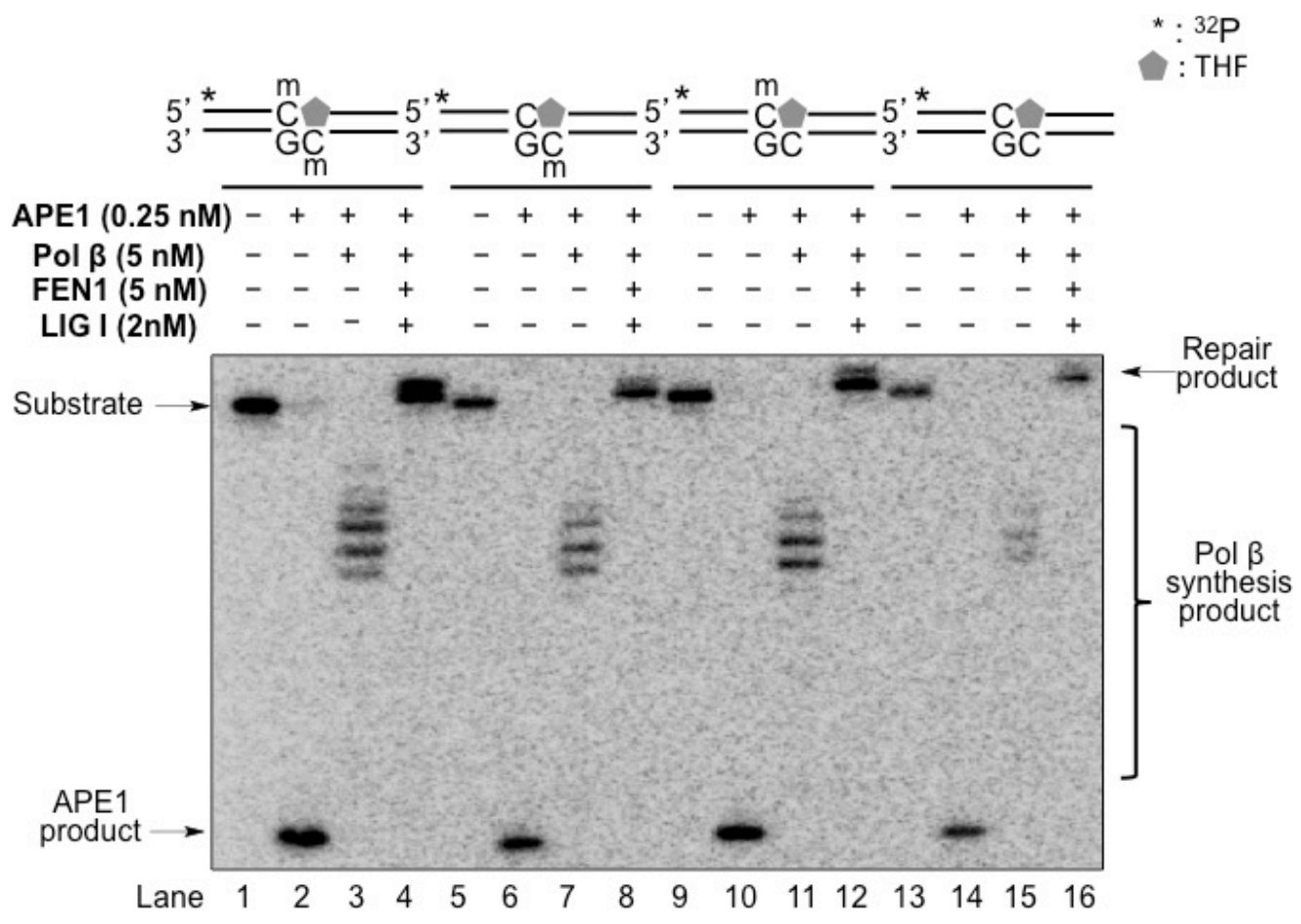

Figure 14. Reconstituted BER in the context of DNA methylation with a limited concentration of APE1 
any stimulatory effect from a $5 \mathrm{mC}$ group on BER capacity (Figure 14). The results showed that no significant difference was detected in BER capacity with the methylated substrates from the unmethylated control substrate (Figure 14, lanes 4, 8, 12 and 16). We then asked if under limited concentration of pol $\beta$ at $0.5 \mathrm{nM}$, a $5 \mathrm{mC}$ could play a role on affecting BER efficiency (Figure 15). BER was reconstituted with $10 \mathrm{nM}$ APE1, $1 \mathrm{nM}$ FEN1 and 5 nM LIG I. We found similar amount of repair products were produced from all four different substrates indicating that that the methyl group does not significantly affect BER capacity in the presence of limited amount of pol $\beta$ (Figure 15, lanes 4, 8, 12 and 16). In conclusion, our results indicate that DNA methylation does not significantly alter BER capacity.

\subsection{Interactions between DNA demethlyation and DNA base lesion and repair}

Because BER plays an essential role in mediating DNA demethylation in mammals by removing a modified base that can be produced by various pathways [44, 58, 61, 64, 65], and $\mathrm{CpG}$ dinucleotides are susceptible to oxidative DNA damage that can readily induce a 8-oxoG at a methylated $\mathrm{CpG}$ dinucleotide, we asked if DNA demethylation mediated by BER can affect repair of a damaged base when the base lesion occurs adjacent to a DNA demethylation intermediate such as a mismatched base pair and if DNA base lesions can affect the efficiency and paths of DNA demethylation. To answer these questions, we characterized a series of BER enzymatic activities and BER capacity in the context of a $\mathrm{T} / \mathrm{G}$ mismatch that results from the AID-mediated DNA demethylation pathway $[4,42,43,59]$. 


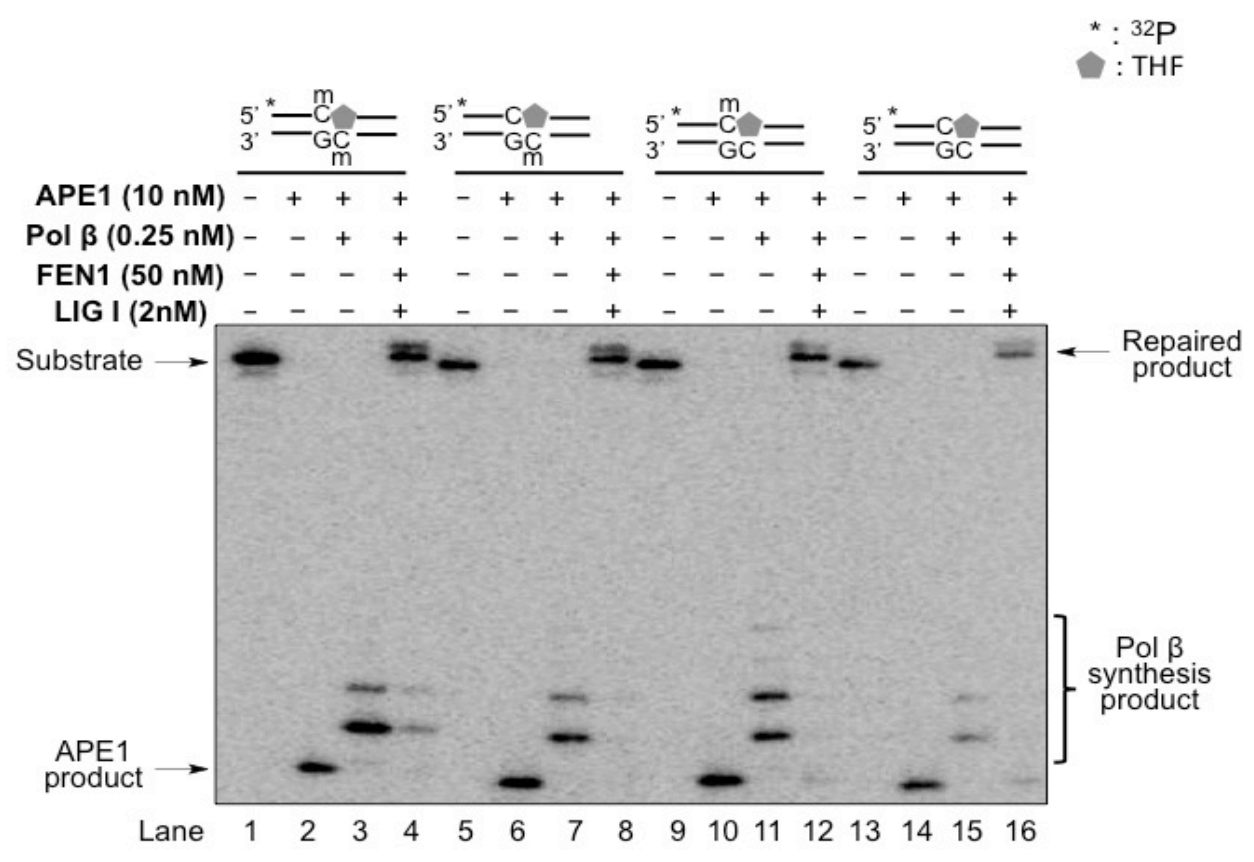

Figure 15. Reconstituted BER in the context of DNA methylation with limited concentration of APE1

3.2.1 TDG efficiently removes the $T$ from a $T / G$ mismatch. Initially, we used an oligonucleotide substrate containing a $\mathrm{T} / \mathrm{G}$ mismatch located in a $\mathrm{CpG}$ dinucleotide (Table I) to establish an assay for thymine DNA glycosylase activity. The substrate containing a $\mathrm{T} / \mathrm{G}$ mismatch mimics a $\mathrm{T} / \mathrm{G}$ mismatch intermediate produced by AID that 
deaminates a 5-methylcytosine converting the methylated base into a thymine (Figure 16). To optimize the condition for TDG to remove the mismatched base pair, increasing concentrations of thymine DNA glycosylase from $25 \mathrm{nM}$ to $150 \mathrm{nM}$ was incubated with $25 \mathrm{nM}$ substrate at $37^{\circ} \mathrm{C}$ for $15 \mathrm{~min}$ (Figure 16, lanes 2-5). The incubation allowed thymine DNA glycosylase to remove the mismatched $\mathrm{T}$ leaving an abasic site. Subsequently excessive amount of APE1 $(50 \mathrm{nM})$ was used to incise the 5'-side of the abasic site to ensure the complete incision of the abasic site, resulting in the production of a $16 \mathrm{nt}$ cleavage product (Figure 16, lanes 2-5). With increasing concentrations of

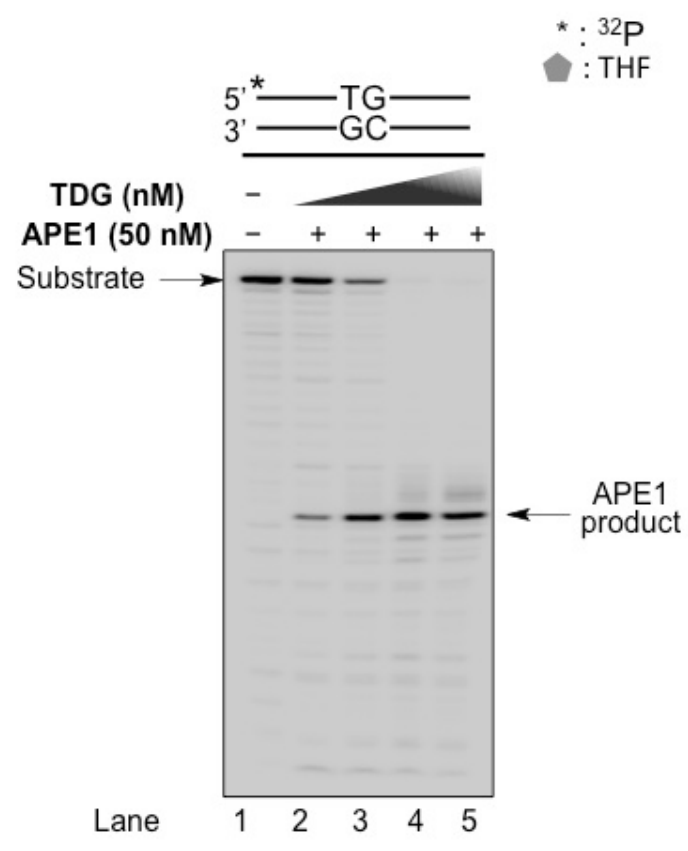

Figure 16. Removal of a 3'-mismatched T by TDG

thymine DNA glycosylase, the amount of the APE1 cleavage product was significantly increased. When the ratio of enzyme-substrate reached 5:1, all the substrate was converted to the product by thymine DNA glycosylase (Figure 16, lanes 2-5). We further identified a lowest concentration for thymine DNA glycosylase to efficiently remove the 
mismatch base pair as $75 \mathrm{nM}$ (data not shown). We then examined the activity of thymine DNA glycosylase in the presence of APE1 to determine if TDG activity can be altered by an abasic site (Figure 17). We found that TDG efficiently removed all mismatched $\mathrm{T}$ that was adjacent to an undamaged base in the presence of a high concentration of APE1 at 50 $\mathrm{nM}$ (Figure 17, lanes 4-9). TDG failed to efficiently remove all mismatched $\mathrm{T}$ that was located adjacent to an abasic site even in the presence of a high concentration of APE1 as the cleavage major product was a $17 \mathrm{nt}$ product that should result from APE1 5'-incision of the abasic site (Figure 17, lanes 13-18, lanes 22-27). Compared with the control group, no cleavage product suggests that TDG removal of a mismatched $\mathrm{T}$ was inhibited.

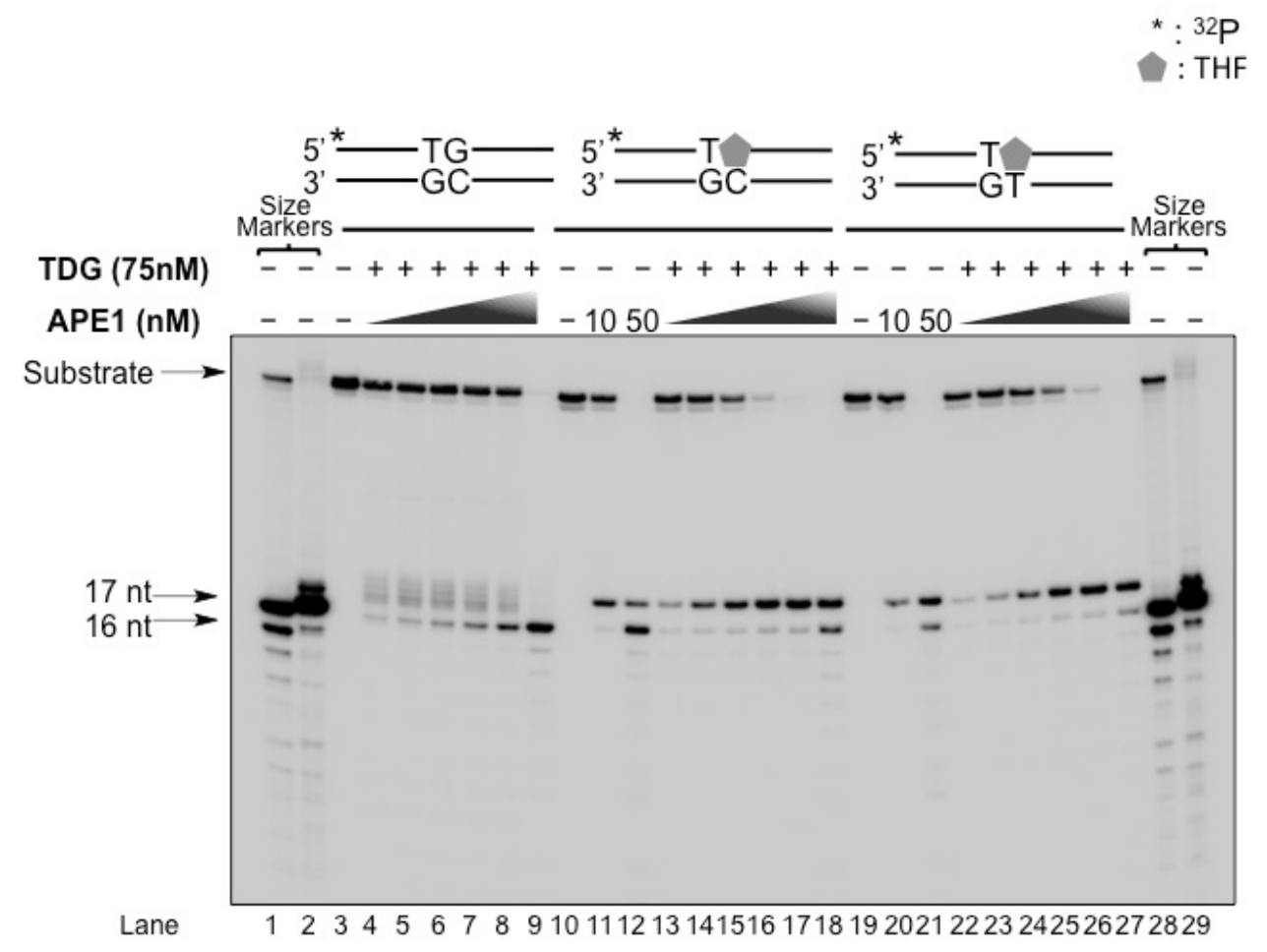

Figure 17. Removal of a 3'-mismatched T by TDG in the presence of APE1

3.2.2 TDG is completely inhibited by an abasic lesion. On the basis of the previous results, to further confirm the effect of an abasic lesion can affect TDG activity, initially 
we examined TDG removal of a 3'-mispaired $\mathrm{T}$ that was adjacent to an abasic site. Substrates containing a 3'-mismatched $\mathrm{T}$ next to an undamaged base or a THF residue (Table I) were incubated with increasing concentrations of TDG ranging from $50 \mathrm{nM}$ to $70 \mathrm{nM}$. The incubation allowed TDG to remove the 3'-mismatched T generating a native abasic site. The abasic site was broken using high temperature into a single-strand break

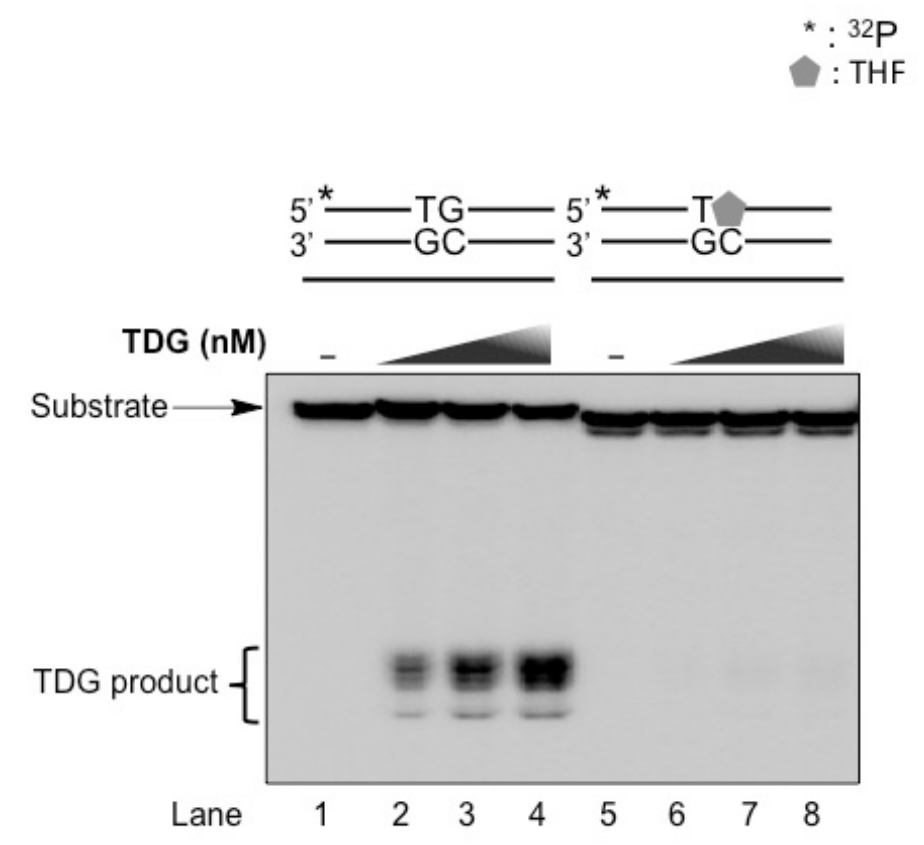

Figure 18. TDG activity is inhibited by an abasic base lesion

for detecting TDG products. The results showed that $50 \mathrm{nM}$ TDG removed the mismatched $\mathrm{T}$ adjacent to a normal base (Figure 18, lane 2). Removal of the base was significantly increased with increasing concentrations of TDG from $60 \mathrm{nM}$ to $70 \mathrm{nM}$ (Figure 18, lanes 3-4). However, no TDG product was generated from a mismatched T adjacent to an abasis site by the same concentrations of the enzyme (Figure 18, lanes 68). Compared to the control group, no product bands indicates that thymine DNA glycosylase activity was completely inhibited by an abasic lesion. 


\subsubsection{APE1 activity is not affected by a 3'-mismatched $T$ in a CpG dinucleotide and}

TDG. To determine any effects from 3'-mismatched T adjacent to an abasic site on APE1 activity, Substrates containing a 3'-T mismatch next to a THF residue that was opposite to an undamaged nucleotide or a thymine were used. This mimics the scenario where a single $5 \mathrm{mC}$ is demethylated or two $5 \mathrm{mCs}$ are demethylated simultaneously. APE1 activity was measured by incubating $5 \mathrm{nM}$ of APE1 in the absence and presence of increasing concentrations of TDG from $10 \mathrm{nM}$ to $75 \mathrm{nM}$ with $25 \mathrm{nM}$ substrates (Figure 19). The results showed that APE1 efficiently incised the 5'-end of an abasic site at the concentration of $5 \mathrm{nM}$ on both types of substrates (Figure 19, lanes 3-6 and lanes 9-12). APE1 activity did not exhibit any difference in the absence and presence of increasing concentrations of TDG indicating that TDG cannot affect APE1 incision of an abasic site.

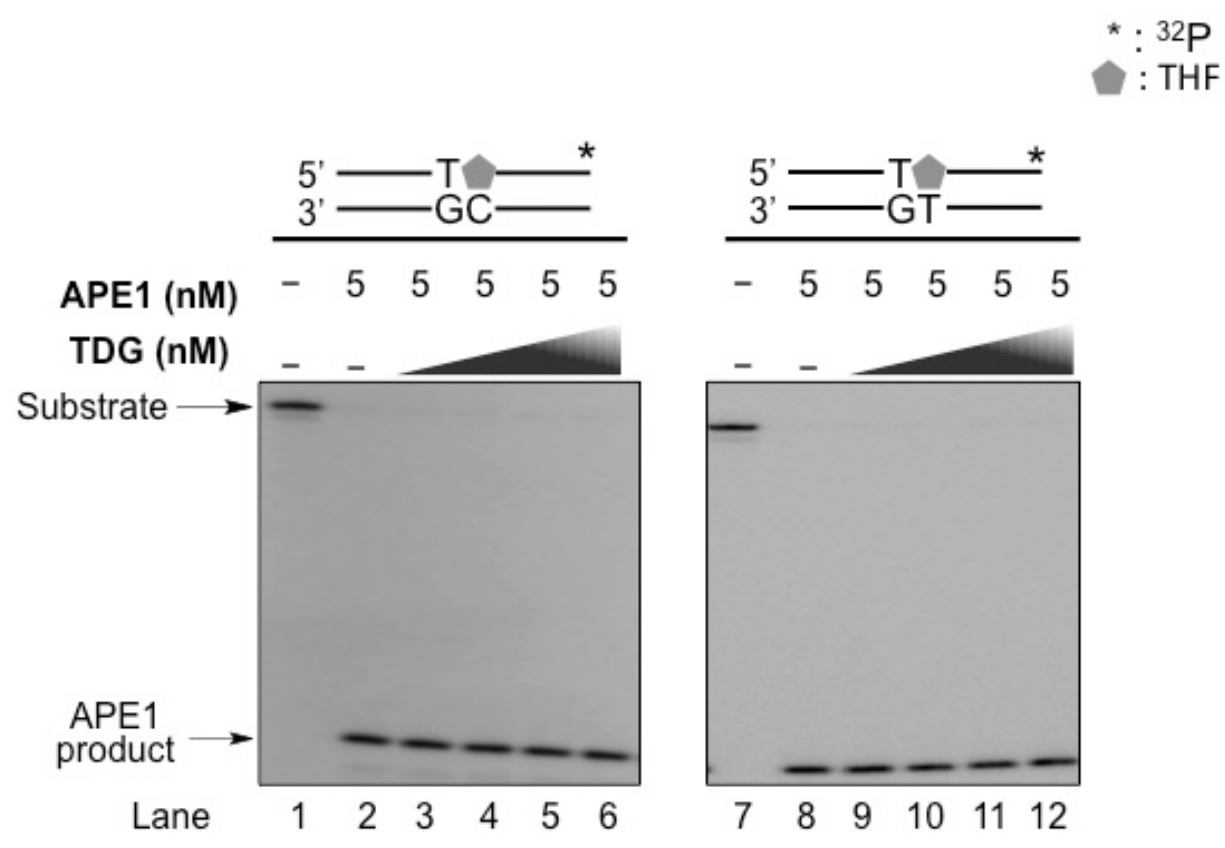

Figure 19. APE1 5'-incision of the abasic site in the presence of TDG 
We conclude that a demethylation intermediate 3'-mismatched T does not affect APE1 5'-incision of an abasic site, and APE1 can efficiently incise an abasic site in the presence of TDG. The high efficiency of APE1 5'-incision further indicates that there is no inhibitory effect of TDG on APE1 5'-incision of an abasic site.

3.2.4 Pol $\beta$ can efficiently extend a 3'-mismatched T. To determine if pol $\beta$ can still perform DNA synthesis in the presence of a 3'-mismatched T, we examined pol $\beta$ gapfilling synthesis using substrates with a 3'-matched $\mathrm{C}$ or a 3'-mismatched $\mathrm{T}$ adjacent to a pre-incised THF residue or a 3'-mismatched T along with a T opposite to a THF residue. Substrates $(25 \mathrm{nM})$ were incubated with various concentrations of pol $\beta$ at $1 \mathrm{nM}, 5 \mathrm{nM}$ and $10 \mathrm{nM}$. At all concentrations tested, pol $\beta$ efficiently inserted one nucleotide to extend a 3'-matched C (Figure 20, lanes 2-4). Surprisingly, pol $\beta$ also extended a 3'-

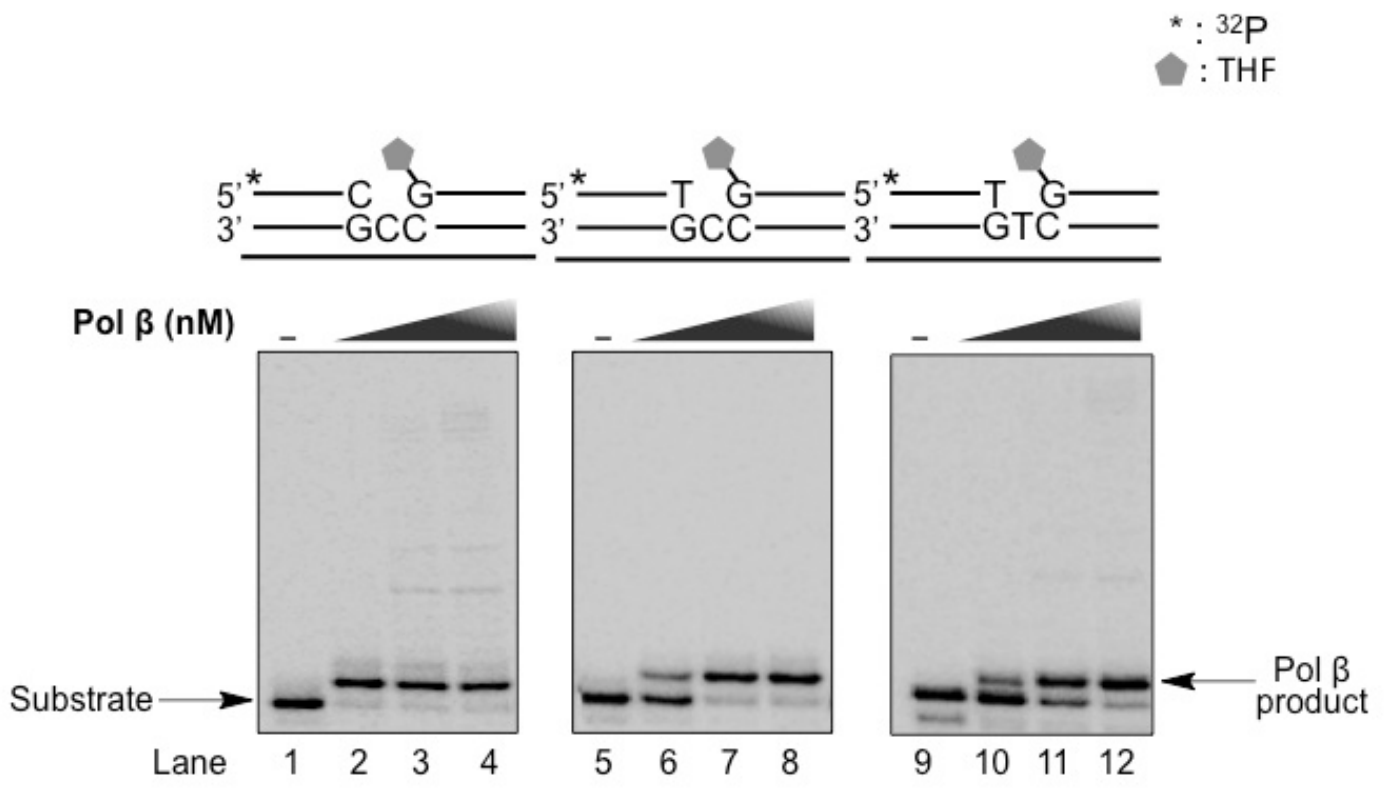

Figure 20. Pol $\beta$ DNA synthesis in the context of a T/G mismatch 
mismatched $T$ efficiently (Figure 20, lanes 6-8 and lanes 10-12). Pol $\beta$ DNA synthesis was particularly obvious at the concentrations of $5 \mathrm{nM}$ and $10 \mathrm{nM}$ where almost all substrates were converted to products (Figure 20, lanes 6-8 and lanes 10-12). Interestingly, pol $\beta$ DNA synthesis to extend a 3'-mismatched T on the substrate with a T opposite the THF residue was much weaker than its synthesis with other substrates suggesting that the polymerase had difficulty to extend a 3 '-mismatched $\mathrm{T}$ when it inserts a next nucleotide to base pair with A or T. The results indicate that pol $\beta$ can extend a 3'mismatched $\mathrm{T}$ suggesting that the polymerase adopts a similar mechanism that is adopted by several DNA translesion synthesis polymerases such as pol4 and pol $\kappa$ that demonstrate mismatch tolerance $[66,67]$. The results also indicate that pol $\beta$ performed a strand-displacement synthesis to extend a 3'-terminus matched C (Figure 20, lanes 2-4), but it failed to perform such synthesis when it extended a 3'-mismatched T suggesting that the mismatched base affects pol $\beta$ further DNA synthesis. In conclusion, pol $\beta$ can tolerate and efficiently extend a 3'-mismatched $\mathrm{T}$ that results from DNA demethylation of a $\mathrm{CpG}$ dinucleotide.

\subsubsection{APE1 3'-5' exonuclease activity efficiently removes a 3'-mispaired $T$ on a $T / G$}

mismatch. It is known that APE1 3'-5' exonuclease activity can remove the mismatched nucleotide [63]. Thus we hypothesize that APE1 can also efficiently remove the 3'terminus mismtached $\mathrm{T}$ from a $\mathrm{T} / \mathrm{G}$ mismatch to increase the fidelity of pol $\beta$. To test this possibility, we examined APE1 activity on substrate $(25 \mathrm{nM})$ with a 3'-terminus mispaired $\mathrm{T}$ at the upstream strand and a 5'-THF residue at the downstream strand with a template $\mathrm{C}$ or $\mathrm{T}$ opposite to an abasic site (Figure 21, lanes 7-10 and lanes 12-15). AP endonuclease 1 cleavage on a substrate containing a THF residue at the 5 '-end of the 
downstream primer and a 3'-C/G matched nucleotide was also examined to determine the activity of APE1 in removing a 3'-terminus matched C (Figure 21, lanes 1-5). We found that APE1 at both low and high concentrations ( $5 \mathrm{nM}, 10 \mathrm{nM}, 25 \mathrm{nM}$ and $50 \mathrm{nM})$ exhibited poor cleavage activity in removing the 3'-terminus matched C (Figure 21, lanes 2-5), indicating that removal of a 3'-terminus matched nucleotide by APE1 3'-5' exonuclease activity was not efficient. Low concentrations of APE1 (5 nM and $10 \mathrm{nM})$ removed the 3'-terminus mismatched $\mathrm{T}$ much more efficiently than it removed a 3'matched $\mathrm{C}$ on a substrate with a template containing $\mathrm{C}$ or $\mathrm{T}$ opposite to a THF residue (Figure 21 lanes 7 and 8, 12 and 13). However, high concentrations of APE1 (25 nM and $50 \mathrm{nM}$ ) removed the 3'-terminus mismatched $\mathrm{T}$ with a high efficiency (Figure 21, lanes 9 and 10, 14 and 15). For all substrates with a T/G mismatch, APE1 mainly removed one

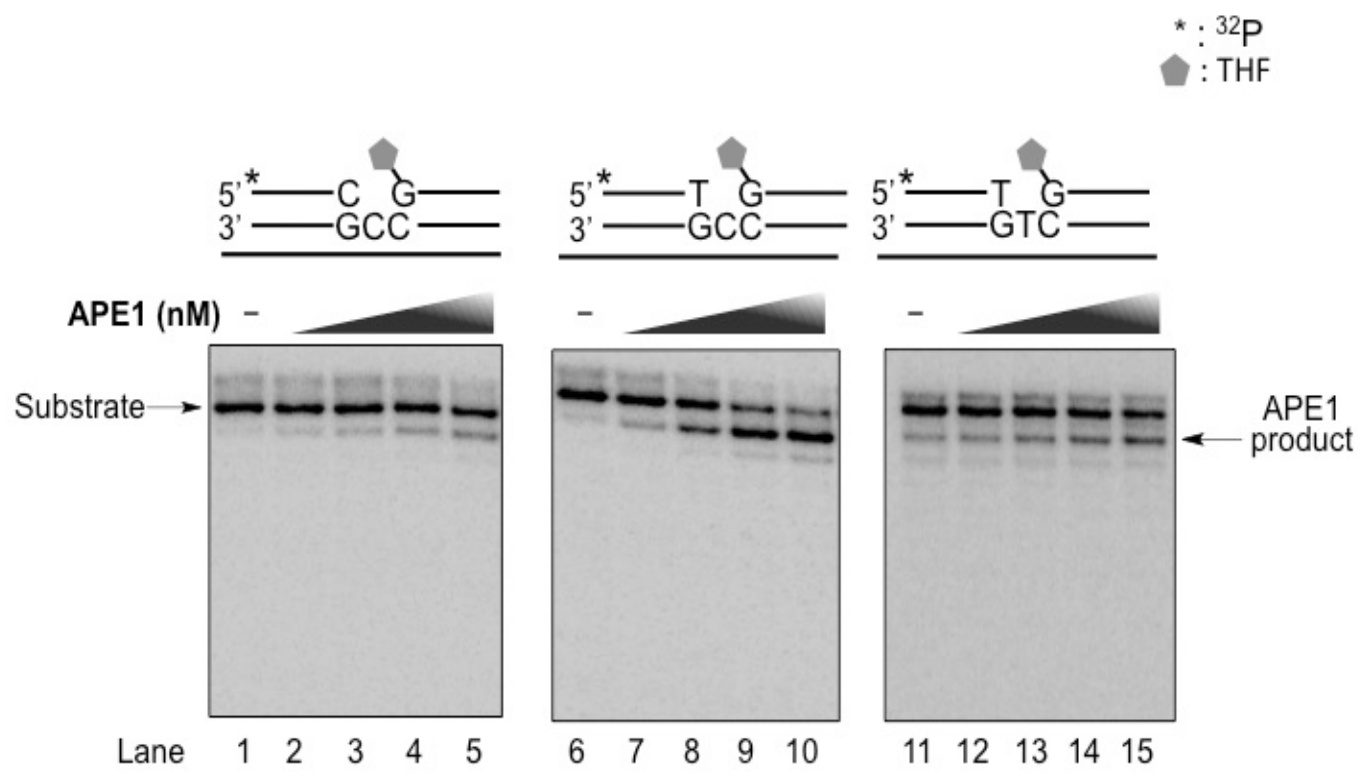

Figure 21. Removal of a 3'-mimatched T by APE1 3'-5' exonuclease activity 
nucleotide from the upstream primer containing a 3 '-terminus mismatched $T$. We conclude that APE1 can efficiently remove the mismatched nucleotide.

\subsubsection{Removal of a 3'-mismatched nucleotide by APE1 3'-5' exonuclease activity} facilitates pol $\beta$ DNA synthesis at a nicked DNA. To further examine whether APE1 3'5' exonuclease can modulate pol $\beta$ DNA synthesis in general, we initially examined its effect on pol $\beta$ DNA synthesis in a nicked DNA with or without a 5'-THF flap that was adjacent to a $\mathrm{T} / \mathrm{C}$ or $\mathrm{C} / \mathrm{C}$ mismatch (Figure 22 ). Pol $\beta$ DNA synthesis was examined using $5 \mathrm{nM}$ pol $\beta$ in the absence or presence of $50 \mathrm{nM}$ APE1 and $75 \mathrm{nM}$ TDG. The results showed that pol $\beta$ alone failed to insert any nucleotides at the nicked DNA substrates (Figure 22, lane 2, 6 and 10). Presence of APE1 allowed pol $\beta$ to insert

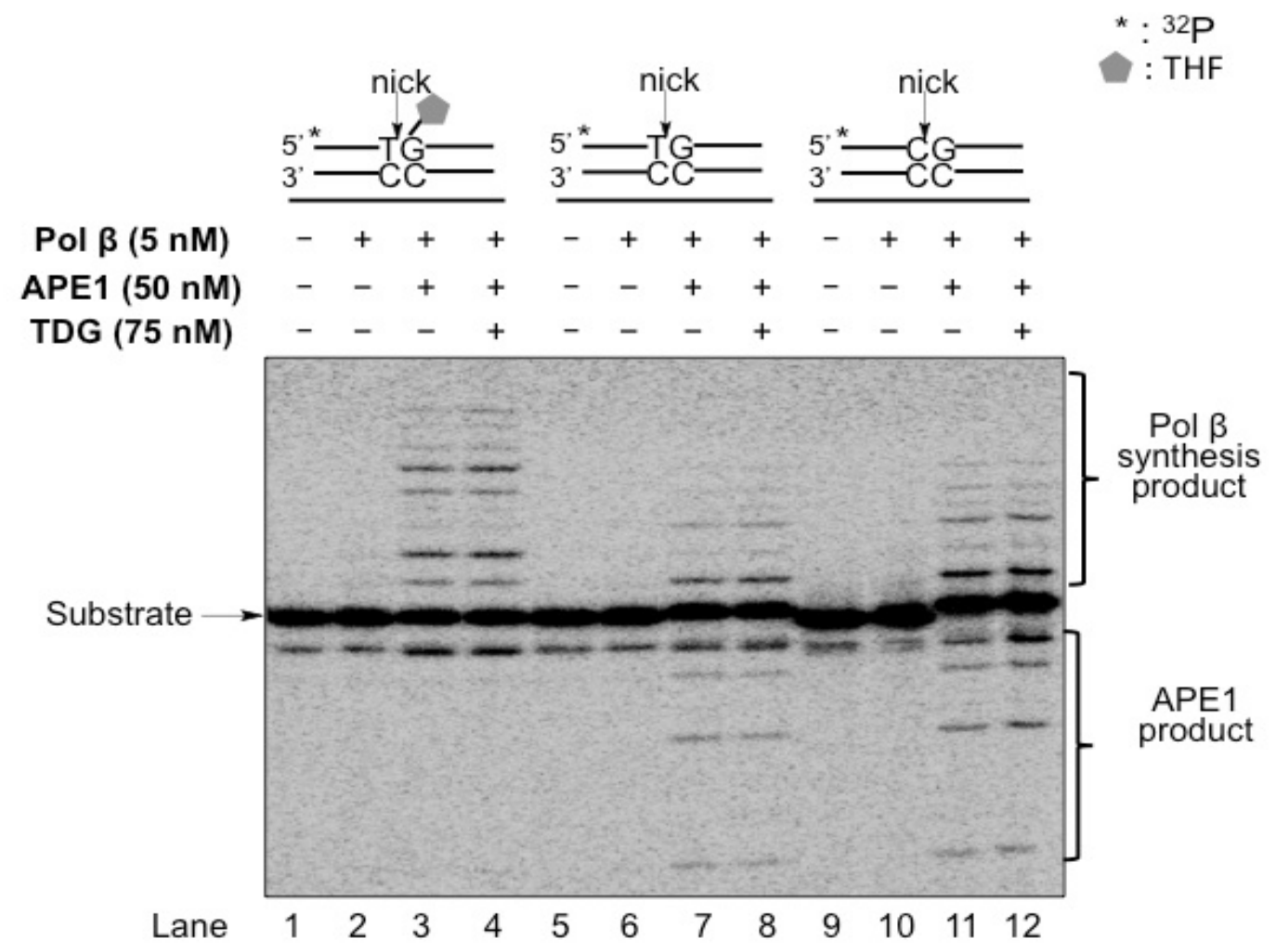

Figure 22. Removal of a 3'-mismatched nucleotide at a nick by APE1 3'-5' exonuclease activity 
multiple nucleotides with all the substrates tested (Figure 22, lanes 3-4, lanes 7-8 and lanes 11-12) indicating that APE1 3'-5' exonuclease removed the mismatched nucleotide leaving a 1 nt gap for pol $\beta$ to fill in. The effect was more evident with the nicked-THF flap substrate (Figure 22, lanes 3-4). For the substrates without a THF flap, APE1 3'-5' exonuclease activity was predominant that somewhat compromised pol $\beta$ DNA synthesis (Figure 22, lanes 7-8 and lanes 11-12). Pol $\beta$ DNA synthesis did not show a difference in the absence and presence of TDG (Figure 22, lanes 3-4, lanes 7-8 and lanes 11-12) indicating that TDG does not affect pol $\beta$ DNA synthesis. We conclude that APE1 3'-5' exonuclease activity facilitates pol $\beta$ DNA synthesis at nicked DNA, and the effect is TDG independent.

\subsubsection{APE1 does not alter pol $\beta$ gap-filling synthesis for extending a 3'-terminus}

mismatched T. Since our previous results demonstrated that APE1 removed a 3'mismatched $\mathrm{T}$ efficiently (Figure 23), we further hypothesize that APE1 may stimulate the gap-filling synthesis and strand displacement synthesis activity of pol $\beta$ by removing the 3'-terminus mismatched $\mathrm{T}$ allowing pol $\beta$ to insert a $\mathrm{C}$ to create a matched $\mathrm{C} / \mathrm{G}$ base pair at the 3'-terminus. Pol $\beta$ then extended the 3'-matched C to continue its subsequent DNA synthesis. We examined the possibility using the substrate $(25 \mathrm{nM})$ with a 3'terminus mispaired $\mathrm{T}$ at the upstream strand and a 5 '-THF residue at the downstream strand with a template $\mathrm{C}$ or $\mathrm{T}$ opposite to the THF residue (Figure 23, lanes 7-18). The substrate with a 3'-terminus matched $\mathrm{C}$ was used as a positive control (Figure 23, lanes 16). No significant difference in the amount of pol $\beta$ DNA synthesis product (Figure 23, lanes 3, 9 and 15) was detected in the absence of APE1 (Figure 23, lanes 3, 9,15) and in 
the presence of $5 \mathrm{nM}, 10 \mathrm{nM}$ and $50 \mathrm{nM}$ APE1 (Figure 23, lanes 4-6, 10-12 and 16-18). Therefore, APE1 did not affect pol $\beta$ gap-filling synthesis at both low and high concentrations.

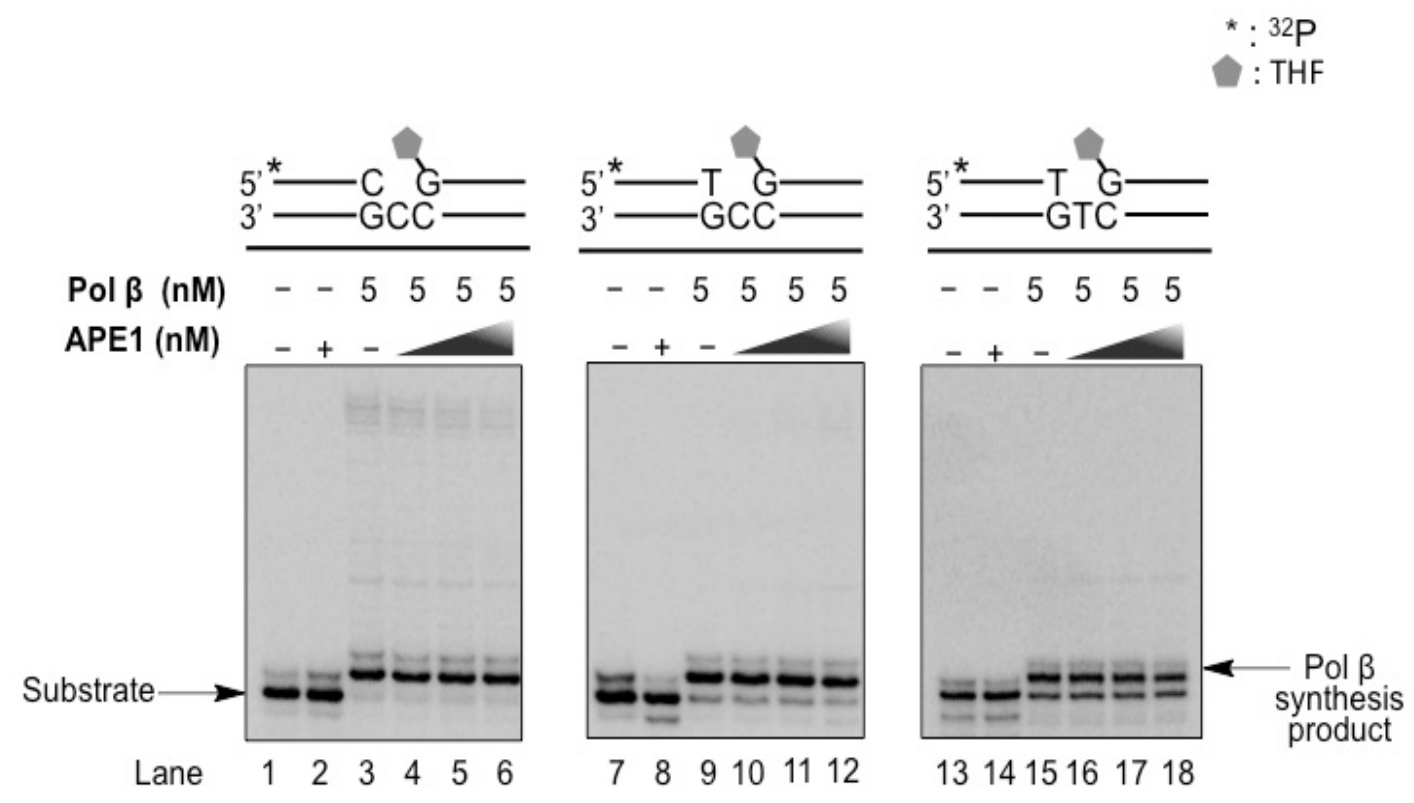

Figure 23. Pol $\beta$ DNA synthesis in the presence of APE1 on substrates containing a $T / G$ mismatch

\subsubsection{The Klenow fragment of $\mathrm{E}$. Coli DNA polymerase I can efficiently remove a 3'-} mismatched T, whereas the 3'-5' exonuclease deficient mutant of Klenow fragment can extend a 3'-mismateched $\boldsymbol{T}$. Since we found that pol $\beta$ efficiently extended and tolerated a 3'-mismatched T, and APE1 3'-5' exonuclease played an important role in removing a mismatched nucleotide before pol $\beta$ can extend the mismatched nucleotide, suggesting that APE1 3'-5'-exonuclease can serve as a proofreading factor to cooperate with pol $\beta$ improving the fidelity of the polymerase. We then asked if a replication DNA polymerase with a 3'-5' exonuclease proof reading domain would have the same function as APE1 3'-exonuclease in removing a mismatched $\mathrm{T}$ in a $\mathrm{CpG}$ dinucleotide and if deficiency of 
the proof reading domain would also lead to the extension of the mismatched nucleotide in a $\mathrm{CpG}$ dinucleotide. We initially characterized the $3^{\prime}-5^{\prime}$ exonuclease activity of Klenow fragment on the substrates containing a THF flap with a 3'-matched C or a 3'mismatched $\mathrm{T}$ with a template $\mathrm{C}$ or $\mathrm{T}$ (Figure 24A). We found that Klenow fragment 3'-5' exonuclease efficiently removed a 3 '-mismatched $\mathrm{T}$ at units ranging from 0.1 to 1 (Figure 24A, lanes 2-5 and lanes 7-10). The enzymatic activity also cleaved nucleotides progressively. Klenow fragment also exhibited cleavage on matched nucleotides (Figure 24A, lanes 12-15). The results indicate that the $3^{\prime}-5^{\prime}$ exonuclease of the replication polymerase can remove both mismatched and matched nucleotides. We then examined the activity of the $3^{\prime}-5^{\prime}$ exonuclease deficient mutant of Klenow fragment on these substrates and found that the mutant enzyme ( $0.1 \mathrm{U}$ to $1 \mathrm{U})$ only exhibited an inefficient cleavage on a 3'-mismatched T and poor cleavage on a matched nucleotide (Figure 24B). The gel result indicates that $3^{\prime}-5$ ' exonuclease of Klenow fragment can efficiently remove a 3'-mismatched $\mathrm{T}$ playing an important role in proofreading for the polymerase. Further analysis of DNA synthesis on these substrates by wild-type and mutant Klenow fragment demonstrated that wild-type enzyme synthesized DNA on both 3'-mismatched and 3 '-matched containing substrates with similarly efficiency generating the same species of product indicating its $3^{\prime}-5^{\prime}$ exonuclease activity removed a $3^{\prime}-$-mismatched $\mathrm{T}$ and allowed the polymerase to insert a correct nucleotide to base pair with a template $G$ preventing mutagenesis resulting from a $\mathrm{T} / \mathrm{G}$ mismatch (Figure 25A and 25B). The 3'-5' exonuclease mutant Klenow fragment efficiently performed DNA synthesis and generated a product one-nucleotide longer than the full length of the template strand (Figure 25B, lanes 47-50 and 52-55), indicating that the mutant Klenow fragment can 
readily extend a 3'-mismatched or it can budge out the mismatched $\mathrm{T}$ to insert a correct nucleotide to base pair with the template $G$ to extend the mismatched $T$. The results further indicate that similar to pol $\beta$, the replication polymerase with its proofreading function deficiency can readily extend a 3'-mismatched T generating mutation.

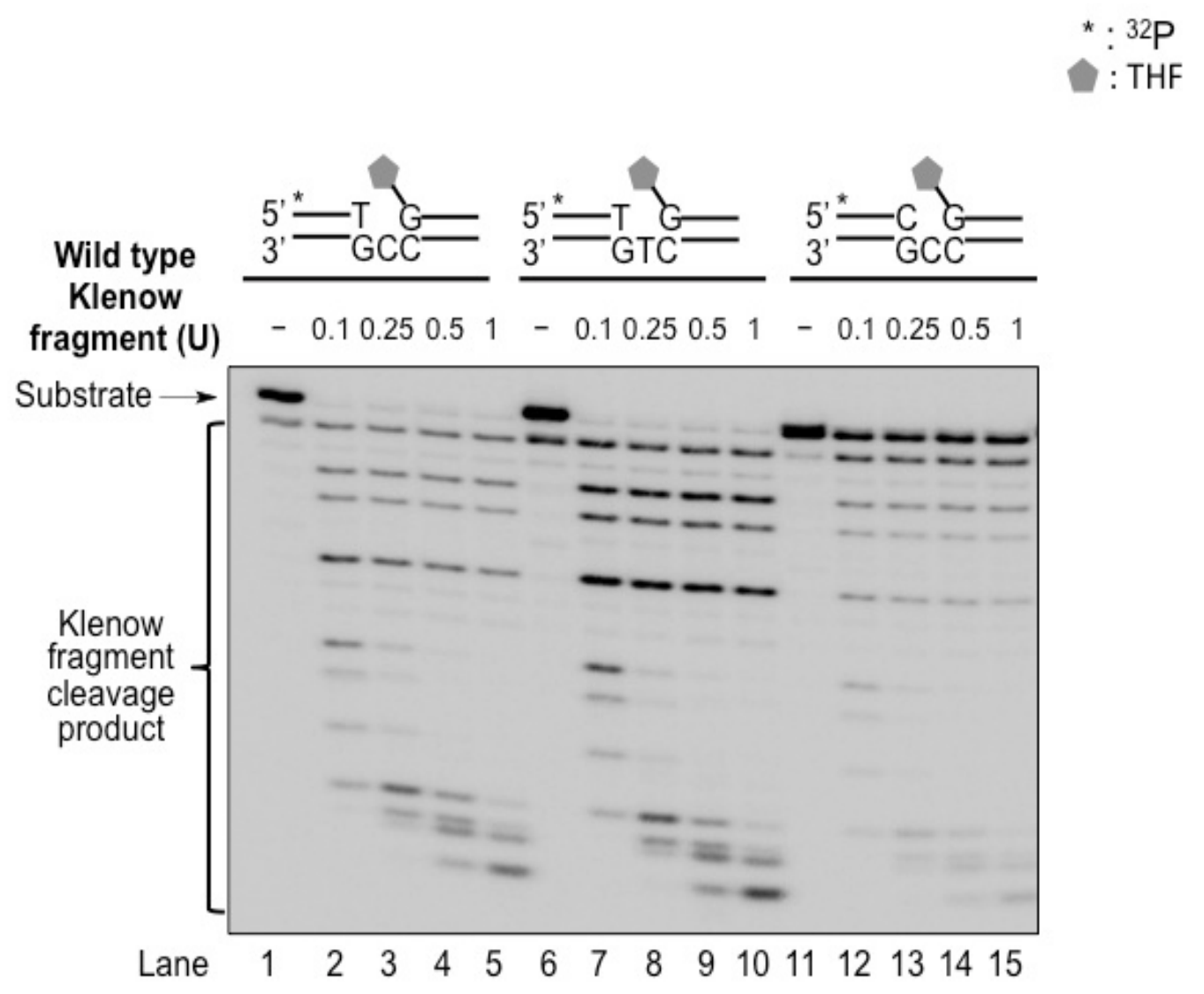

Figure 24A. Wild type Klenow fragment's 3'-5' exonuclease activity 


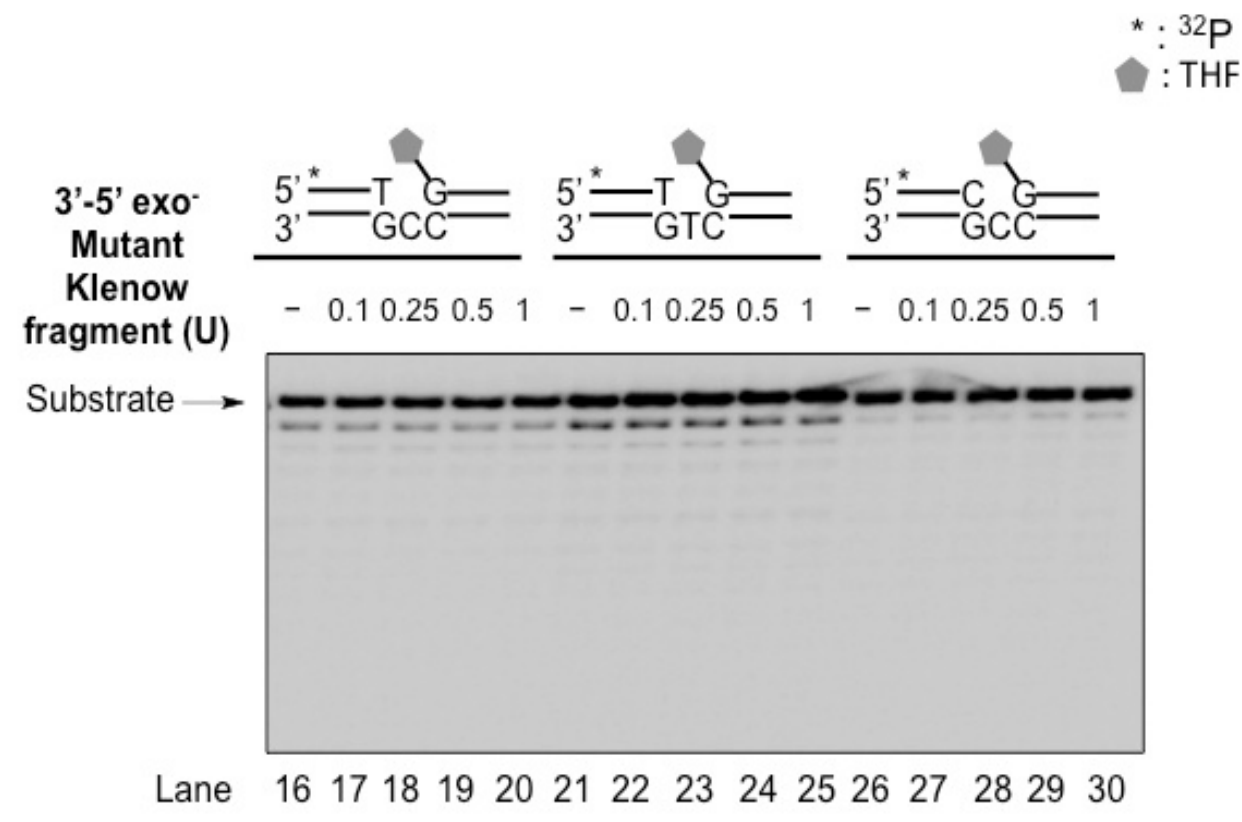

Figure 24B. 3'-5' exo' mutant Klenow fragment's 3'-5' exonuclease activity

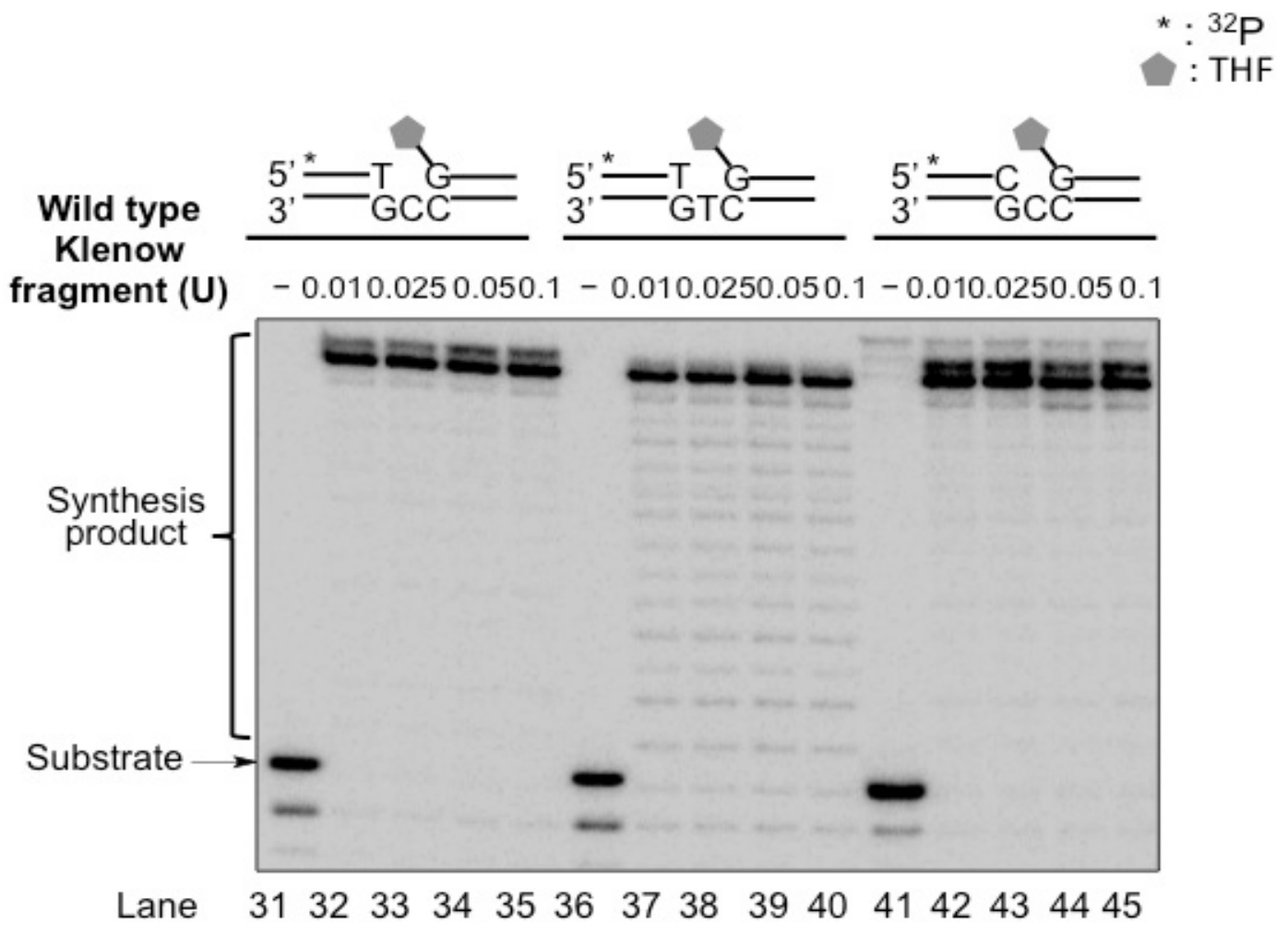

Figure 25A. Wild type Klenow fragment's DNA synthesis activity assay 


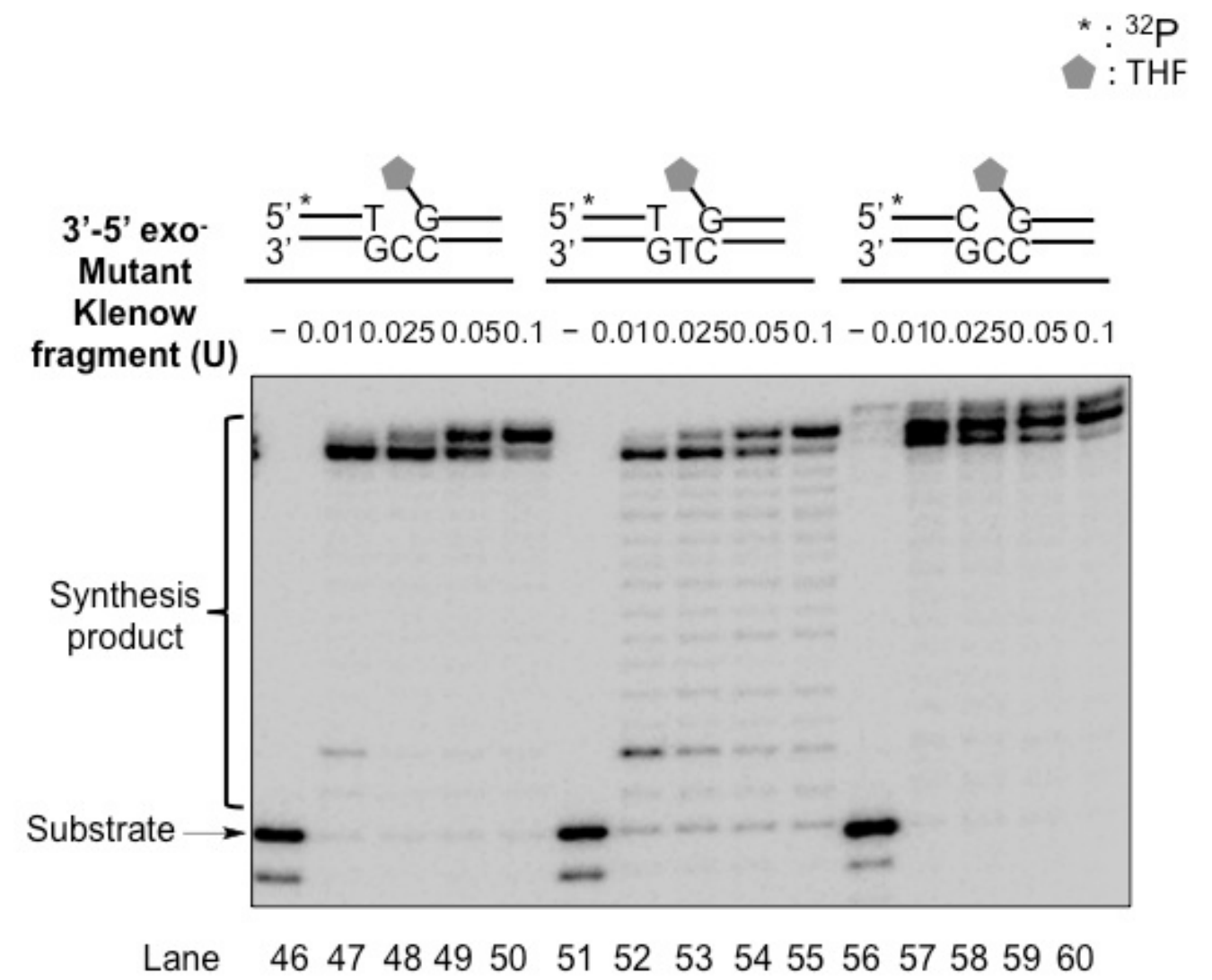

Figure 25B. 3'-5' exo- mutant Klenow fragment's DNA synthesis activity assay

\subsubsection{The efficiency of pol $\beta$ to extend a 3'-mismatched T and APE1 3'-5' exonuclease}

to remove a 3'-mismatched nucleotide. Since our previous results indicate that removal of a 3'-mismatched T by APE1 is critical in improving pol $\beta$ fidelity, we asked if APE1 can remove the mismatch $\mathrm{T}$ before pol $\beta$ can extend the mismatched nucleotide. We examined the efficiency of pol $\beta$ DNA synthesis at $5 \mathrm{nM}$ and that of APE1 3'-5' exonuclease activity at $5 \mathrm{nM}$ and $50 \mathrm{nM}$ using a substrate $(25 \mathrm{nM})$ containing a 3'mispaired $\mathrm{T}$ at the upstream primer and a 5'-THF residue at the downstream primer with a template $\mathrm{C}$ opposite to a THF residue. The products were measured at different time intervals ranging from 0 min to $30 \mathrm{~min}$. The percentage of products was plotted against incubation time (Figure 26). The result have shown that $5 \mathrm{nM}$ pol $\beta$ extended a 3'- 
mismatched T much faster than APE1 3'-5' removed the mismatched T. However the 3'5 ' exonuclease activity of $50 \mathrm{nM}$ APE1 removed the mismatched T much faster than 5 $\mathrm{nM}$ pol $\beta$ to extend the mispaired base (Figure 26). Removal of the T/G mismatch by AP endonuclease 1 indicates high concentration of APE1 can combat pol $\beta$ extension of a mispaired nucleotide. Since APE1 is much more abundant than pol $\beta$ in cells, the result indicates that APE1 can remove a mismatched T before it can extended by pol $\beta$ in cells.

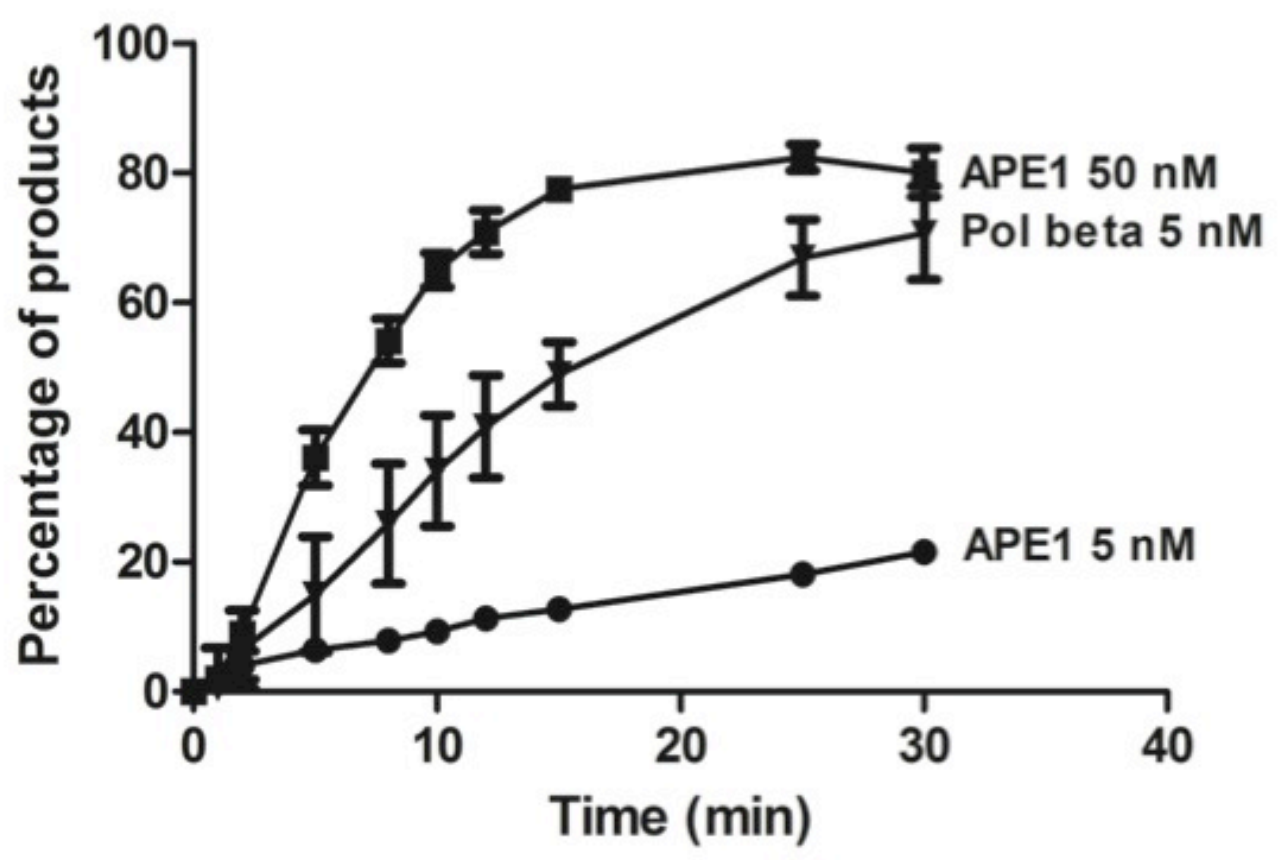

Figure 26. Efficiency of APE1 3'-5' exonuclease and pol $\beta$ extension of a mismatched T

\subsubsection{FEN1 failed to efficiently cleave a sugar phosphate flap in the context}

of a T/G mismatch. Since our previous results indicate that both APE1 and pol $\beta$ activities were not affected by a $3^{\prime}$-mismatch $\mathrm{T}$, we wanted to examine whether it can influence FEN1 flap cleavage activity using a series of substrates containing a 3'- 
mismatched T (Figure 27). The substrate with a 3'-matched $\mathrm{C}$ was used as a control. To

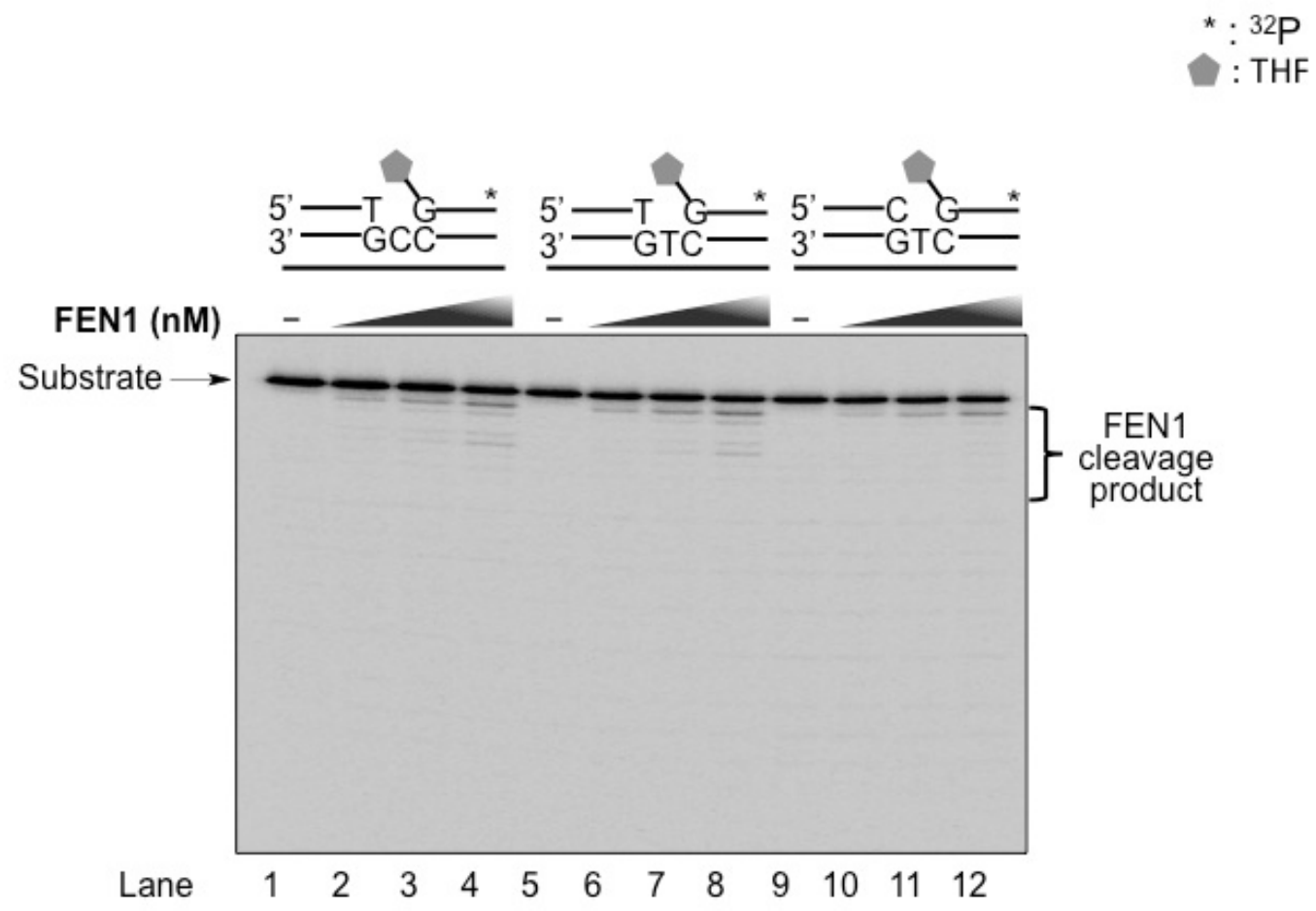

Figure 27. FEN1 cleavage in the context of a T/G mismatch in the absence of pol $\beta$ examine whether 3'-mismatched $\mathrm{T}$ will have any effect on FEN1 cleavage, various substrates $(25 \mathrm{nM})$ were incubated with increasing concentrations of FEN1 from 5 to 25 nM. The results showed that at all concentrations tested, FEN1 along cleaved on the substrates inefficiently (Figure 27, lanes 2 to 4,6 to 8 and 10 to 12). No significant difference was detected between FEN1 cleavage on the mismatch containing substrates and the substrate without a mismatch. In the presence of pol $\beta$, more cleavage FEN1 products were detected from the substrate without a mismatch (Figure 28, lanes 5-7) indicating that pol $\beta$ strand-displacement synthesis created a longer flap for FEN1 cleavage. However, the presence of pol $\beta$ did not significantly improve FEN1 cleavage 
on a flap next to a 3'-mismatched T (Figure 28, lanes 12-14 and lanes 19-21). The low efficiency of FEN1 indicates a 3'-mismatched T exhibited an inhibitory effect on FEN1 cleavage.

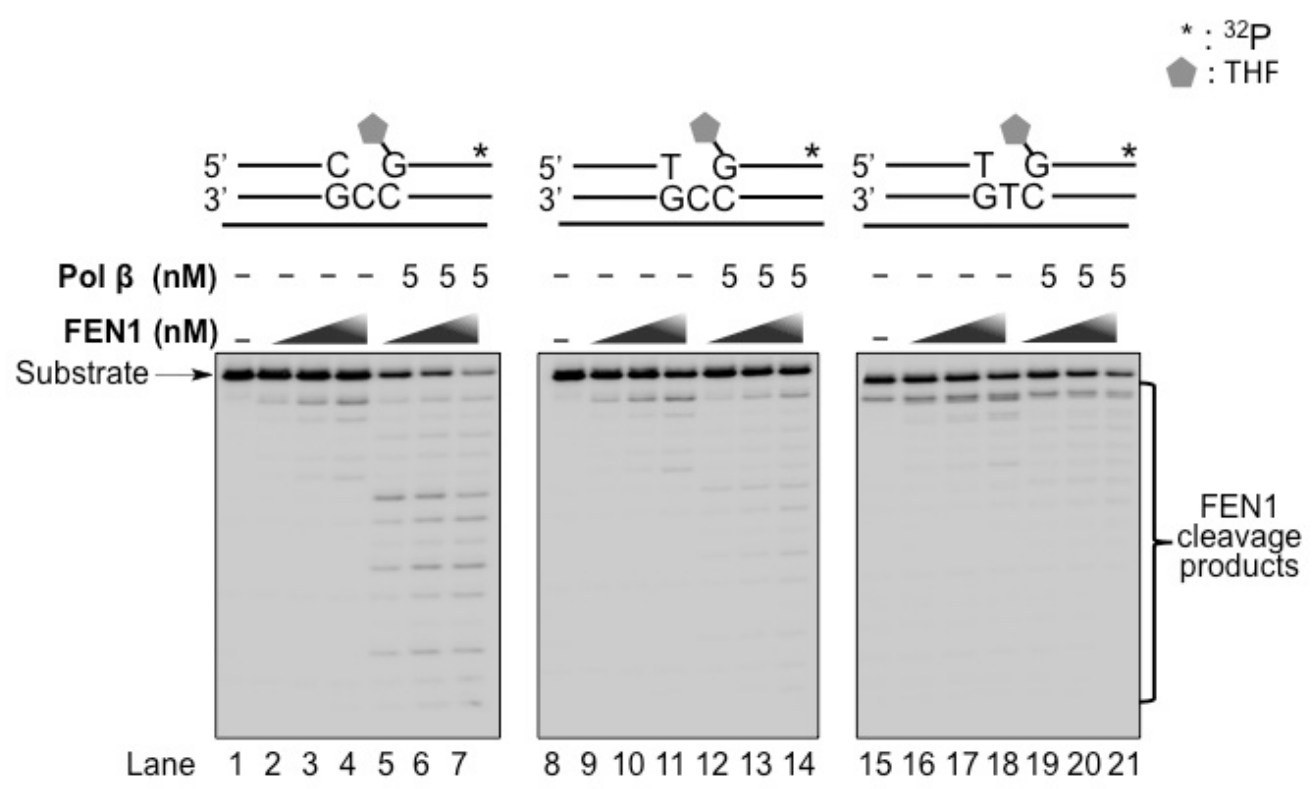

Figure 28. FEN1 cleavage in the context of a T/G mismatch in the presence of pol $\beta$

\subsubsection{Base excision repair can occur in the presence of a 3'-mismatched $T$. Our}

previous results have shown that 3'-mismatched $\mathrm{T}$ does not have influence on the efficiency of pol $\beta$ and APE1 enzymatic activity, however, it slightly inhibited FEN1 flap cleavage efficiency, we wanted to further examine whether the 3'- mismatched T/G may affect BER capacity. We performed enzyme reconstitution experiments by incubating the mismatch-containing substrates and the control substrate without any mismatches with APE1, pol $\beta$, FEN1 and LIG I (Figure 29). The results showed that a BER product was detected with the substrates containing a 3'-mismatched $\mathrm{T}$ in the absence of APE1 (Figure 29 , lanes 6 and 10) although the amount of the product was less than the one generated 
from the control substrate (Figure 29, lane 2). Pol $\beta$ DNA synthesis indicates that in the absence of APE1, a 3'-mismatched T can be extended by pol $\beta$ leading a repair product with a mismatched base pair. Presence of high concentrations of APE1 (50 nM and 100 $\mathrm{nM}$ ) significantly stimulated the production of the repair product (Figure 29, lanes 7-8) from the substrate with a $3^{\prime}$-mismatched $\mathrm{T}$ and a template $\mathrm{C}$. However, pol $\beta$ DNA synthesis was not observed with the substrate with a $3^{\prime}$-mismatched $\mathrm{T}$ and a template $\mathrm{T}$ (Figure 29, lanes 11-12). We conclude that DNA base lesion repair can be accomplished with a tolerance of a 3'-mismatched $\mathrm{T}$ that is mediated by pol $\beta$ leading to mutagenesis. However this effect can be combated by a high concentration of APE1 3'-5' exonuclease that can efficiently remove a 3'-mismatched nucleotide thereby improving pol $\beta$ fidelity and preventing mutagenesis.

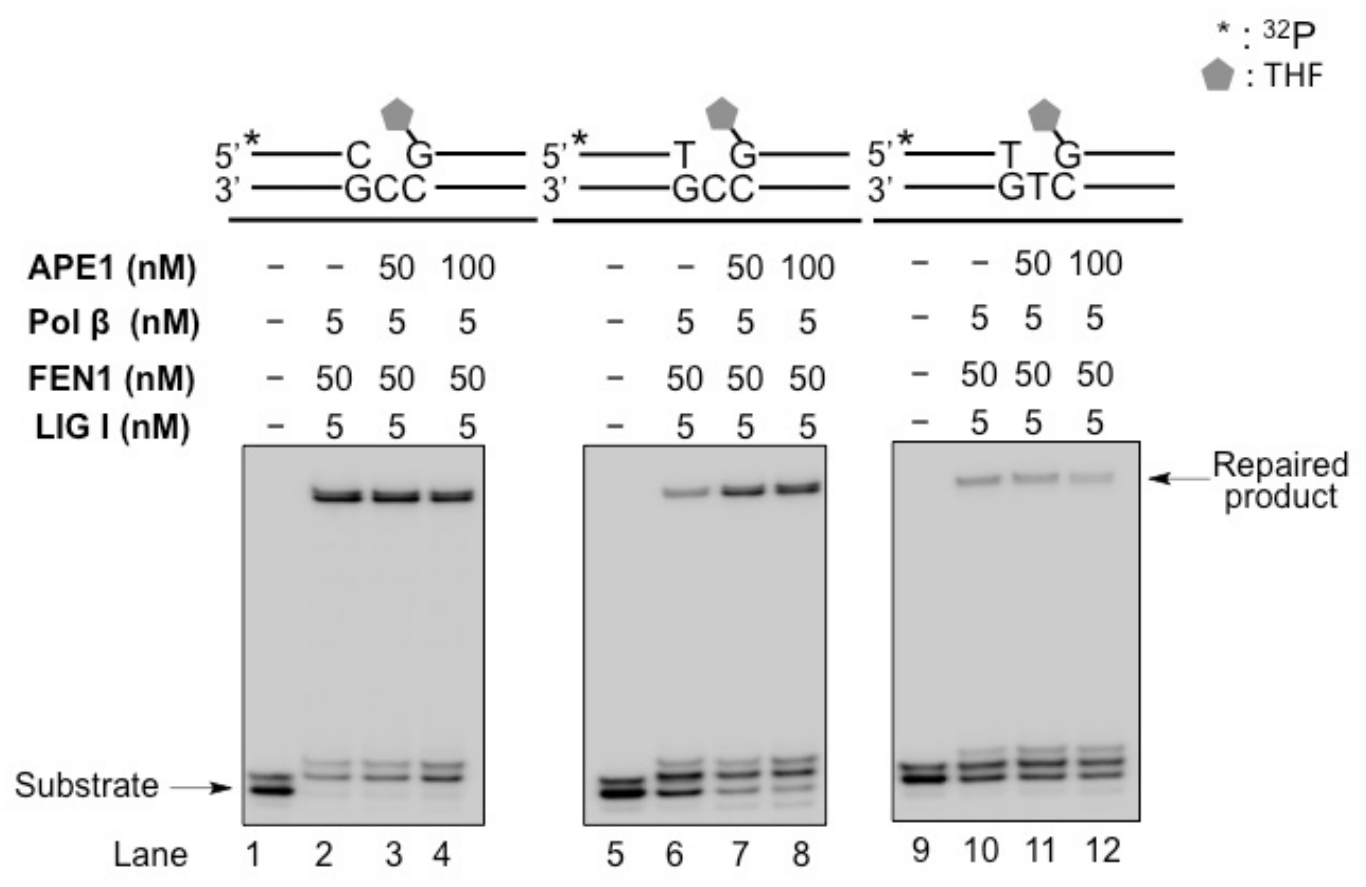

Figure 29. Reconstituted BER in the context of a T/G mismatch in the absence or presence of $50 \mathrm{nM}$ and $100 \mathrm{nM}$ APE1 


\section{Discussion}

4.1 DNA methylation has no effect on BER - In the present study, we systematically characterized the effects of DNA methylation on the core BER enzymes that include APE1, pol $\beta$, FEN1 and LIG I as well as its effect on BER capacity. We found that a $5 \mathrm{mC}$ located adjacent or opposite to an abasic site did not significantly influence the activities of the major BER enzymes (Figure 5-15). Interestingly we found that a $5 \mathrm{mC}$ slightly stimulated pol $\beta$ DNA synthesis in the presence of FEN1 suggesting that it facilitates pol $\beta$-FEN1 coordination during long-patch BER. However, this effect did not lead to a significant effect on total BER capacity indicating that DNA methylation does not interfere with or stimulate repair of a DNA base lesion adjacent or opposite to a $5 \mathrm{mC}$. Our results are consistent with a recent finding by the Wilson group showing that a $5 \mathrm{mC}$ adjacent to an 8-oxoG at a $\mathrm{CpG}$ dinucleotide failed to affect the removal of the base lesion by OGG1 [68]. This further suggests that a DNA base lesion can be efficiently repaired in the presence of DNA methylation.

\subsection{Removal of a T/G mismatch generated by a DNA demethylation pathway is} inhibited by an abasic lesion and pol $\beta$ can extend the 3 '-mismatched $T$ - In this study, for the first time, we studied a scenario where oxidative DNA base lesions occur along with DNA demethylation that generates a $\mathrm{T} / \mathrm{G}$ mismatch from a $5 \mathrm{mC}$ of a $\mathrm{CpG}$ dinucleotide located adjacent or opposite to the base lesions. Both 3'-mismatched $\mathrm{T}$ and damaged bases can be subject to BER. The 3'-mismatched T can be removed by TDG. With the presence of a base lesion adjacent to the 3'-mismatched $\mathrm{T}$, this initiates BER in the context of a base lesion. We found that a 3'-mismatched T did not affect APE1 5'incision of an abasic lesion indicating the base lesion does not affect removal of abasic 
site. Surprisingly, however, we found that the abasic lesion completely inhibited the activity of TDG in removing the 3 '-mismatched $\mathrm{T}$ indicating a base lesion adjacent to the mismatched nucleotide completely disrupts the ability of TDG to remove the mismatched T. This allows the maintenance of the mismatched nucleotide. More surprisingly, we found that pol $\beta$ efficiently extended the 3'-mismatched $T$ thereby maintaining the mispaired base. Thus the repair product generated by the process bears a $\mathrm{T} / \mathrm{G}$ mismatch and may introduce mutations during subsequently DNA replication process.

\subsection{Tolerance of 3'-mismatched T by Pol $\beta$ and other DNA polymerases - Studies from}

the Sweasy group have shown that pol $\beta$ is a low fidelity enzyme in gap-filling synthesis and strand displacement synthesis and can extend a mismatched nucleotide to tolerate mismatches and insert the incorrect nucleotide to bypass a DNA lesion at DNA template strand [69]. A group of DNA polymerases, translesion synthesis polymerase such as pol $\kappa$ has also been found to extend a 3'-mispaired termini using similar pattern of mismatch tolerance [66]. Another translesion synthesis polymerase pol $\mu$ has also been found to be able to extend a 3'-mismatched nucleotide $[70,71]$. Our discovery of pol $\beta$ to extend a 3'mismatched nucleotide demonstrating that pol $\beta$ can adopt a similar mechanism as translesion DNA polymerases. Since our results indicate that pol $\beta$ exhibited an efficient extension of a 3'-mismatched $\mathrm{T}$ to fill in a gapped DNA during BER, and the mismatch tolerance of pol $\beta$ can lead to fully repaired product that bears a mismatch, it is important for further identify a mechanism for removing the mismatched nucleotide before pol $\beta$ extends it. Interestingly, by characterizing the ability of a DNA replication polymerase, the Klenow fragment of bacterial DNA polymerase I, we found that its 3'-5' exonuclease

deficient mutant can also readily tolerate a 3'-mismatched T generating a DNA strand 
that bears a mismatch. These results evidently indicate that a 3'-5' exonuclease for the proofreading function of DNA replication or repair polymerase is essentially needed for removing a $\mathrm{T} / \mathrm{G}$ mismatch at a $\mathrm{CpG}$ dinucleotide resulting from DNA demethylation.

\subsection{APE1 3'-5' exonuclease removes a 3'-mismatched $T$ and prevents pol $\beta$ extension} of the mismatched nucleotide performing a proofreading function - It was reported by the Cheng group that APE1's 3'-5' exonuclease activity is critical in removing a 3'misparied nucleotide in DNA [72]. APE1 3'-5' exonuclease activity in removing a 3'mismatched nucleotide is significantly higher ( 160 fold) than that in removing a matched nucleotide [72]. Thus, it has been proposed that APE1 plays a critical role in correcting the mismatch introduced by error-prone pol $\beta$. This has been supported by our results showing that high concentrations of APE1 removed the 3'-mismatched T more efficiently than pol $\beta$ extension of the 3'-mismatched nucleotide. Since in cells, APE1 is much more abundant than pol $\beta$, this further indicates that APE1 3'-5' exonuclease activity can cooperate with pol $\beta$ to allow the polymerase to insert the correct nucleotide after APE1 removes the mismatched nucleotide. Our results support the notion that APE1 serves as a proofreading function to increase pol $\beta$ fidelity by removing a mismatched nucleotide. Besides, as our results have shown that pol $\beta$ DNA synthesis in the context of matched $\mathrm{C} / \mathrm{G}$ base pair is more efficient than mismatched $\mathrm{T} / \mathrm{G}$ (Figure 20), thus removal of a mismatched T by APE1 will increase pol $\beta$ 's efficiency of DNA synthesis and accelerate insertion of the correct nucleotide to form a repaired product without a mismatch. Thus, sufficient amount of APE1 in cells should lead to a reduced mutation frequency resulting from DNA demethylation through pol $\beta$-dependent BER sustaining genome stability [62]. 


\subsection{DNA demethylation on both strand of genes located on the CpG islands results in}

mutation that could not be corrected by BER - In a scenario where 3'-mismatched $\mathrm{T}$ is adjacent to an abasic site in a $\mathrm{CpG}$ dinucleotide, the potential $\mathrm{T} / \mathrm{G}$ mismatch mutation can be diminished by BER as long as APE1 removes the mismatched T before pol $\beta$ can extend it. However, in the scenario of DNA demethylation occurs on the template strand of a $\mathrm{CpG}$ dinucleotide creating a $\mathrm{T}$ opposite an abasic site, a conversion of $\mathrm{G} / \mathrm{C}$ base pair will occur during BER, thereby introducing an A/T mutation. In this case, APE1 3'-5' exonuclease cannot remove the T. Pol $\beta$ gap-filling synthesis will lead to the conversion of $\mathrm{G} / \mathrm{C}$ base pair into an $\mathrm{A} / \mathrm{T}$ base pair causing a mutation. Here we have provided the first evidence as to how a DNA demethylation contributes to mutations in $\mathrm{CpG}$ islands. 


\section{Table I Oligonucleotide sequence}

\begin{tabular}{lll}
\hline Oligonucleotides & nt & Sequence (5'-3') \\
\hline Downstream & & \\
D1 & 31 & CTG CAG CTG ATG C5mCU GGT GCG GAT CCG GTG C \\
D2 & 31 & CTG CAG CTG ATG C5mCTHF GGT GCG GAT CCG GTG C \\
D3 & 31 & CTG CAG CTG ATG CCU GGT GCG GAT CCG GTG C \\
D4 & 31 & CTG CAG CTG ATG CCTHF GGT GCG GAT CCG GTG C \\
D5 & 17 & THF-GGG TGC GGA TCC GGT GC \\
D6 & 16 & THF-GGT GCG GAT CCG GTG C \\
D7 & 17 & GGG TGC GGA TCC GGT GC \\
D8 & 31 & CTG CAG CTG ATG C5mCTHF GGT GCG GAT CCG GTG C \\
D9 & 31 & CTG CAG CTG ATG C5mCU GGT GCG GAT CCG GTG C \\
D10 & 31 & GCA CCG GAT CCG CAC CTG GCA TCA GCT GCA G \\
D11 & 31 & GCA CCG GAT CCG CAC CTTHF GCA TCA GCT GCA G \\
D12 & 13 & THF-GCA TCA GCT GCA G \\
D13 & 15 & THF-GTG CGG ATC CGG TGC \\
D14 & 15 & GTG CGG ATC CGG TGC \\
D15 & 33 & THF-GCA TCA GCT GCA GTA CGT AGA CTT ACT CAT TGC \\
\hline Template & & \\
T1 & 31 & GCA CCG GAT CCG CAC CCG GCA TCA GCT GCA G \\
T2 & 31 & GCA CCG GAT CCG CAC C5-mCG GCA TCA GCT GCA G \\
T3 & 31 & CTG CAG CTG ATG CCG GGT GCG GAT CCG GTG C \\
T4 & 31 & CTG CAG CTG ATG CTG GGT GCG GAT CCG GTG C \\
T5 & 31 & GCA CCG GAT CCG CAC CGC GCA TCA GCT GCA G \\
T6 & 71 & GCA ATG AGT AAG TCT ACG TAC TGC AGC TGA TGC CGG \\
T7 & & GTG CGG ATC CGG TGC TAC GGA TGC TAG ATG ACT CG \\
& 71 & GCA ATG AGT AAG TCT ACG TAC TGC AGC TGA TGC TGG \\
\hline Upstream & & GTG CGG ATC CGG TGC TAC GGA TGC TAG ATG ACT CG \\
U1 & & \\
U2 & & \\
U3 & & \\
U4 & & \\
U5 & 14 & CTG CAG CTG ATG C5mC \\
U6 & 14 & CTG CAG CTG ATG CC \\
U7 & 15 & CTG CAG CTG ATG C5mCG \\
U8 & 15 & CTG CAG CTG ATG CCG \\
U9 & 17 & GCA CCG GAT CCG CAC CT \\
U10 & 17 & GCA CCG GAT CCG CAC CC \\
& 16 & CTG CAG CTG ATG CGC T \\
\hline & 37 & CTG CAG CTG ATG CGC C \\
& 37 & T GTC ATC TAG CAT CCG TAG CAC CGG ATC CGC ACC \\
& & CGA GTC ATC TAG CAT CCG TAG CAC CGG ATC CGC ACC \\
\hline
\end{tabular}

F: tetrahydrofuran; 5mC: 5-methylcytosine, U: deoxyuridine 


\section{References}

1. Antequera, F. and A. Bird, Number of $C p G$ islands and genes in human and mouse. Proceedings of the National Academy of Sciences of the United States of America, 1993. 90(24): p. 11995-9.

2. $\quad$ Barrett, T.E., et al., Crystal structure of a G:T/U mismatch-specific DNA glycosylase: mismatch recognition by complementary-strand interactions. Cell, 1998. 92(1): p. 117-29.

3. Ehrlich, M., et al., Amount and distribution of 5-methylcytosine in human DNA from different types of tissues of cells. Nucleic acids research, 1982. 10(8): $\mathrm{p}$. 2709-21.

4. Bhutani, N., D.M. Burns, and H.M. Blau, DNA demethylation dynamics. Cell, 2011. 146(6): p. 866-72.

5. Liu, Y. and S.H. Wilson, DNA base excision repair: a mechanism of trinucleotide repeat expansion. Trends in biochemical sciences, 2012. 37(4): p. 162-72.

6. Widschwendter, M., 5-methylcytosine--the fifth base of DNA: the fifth wheel on a car or a highly promising diagnostic and therapeutic target in cancer? Disease markers, 2007. 23(1-2): p. 1-3.

7. Watt, F. and P.L. Molloy, Cytosine methylation prevents binding to DNA of a HeLa cell transcription factor required for optimal expression of the adenovirus major late promoter. Genes \& development, 1988. 2(9): p. 1136-43.

8. Cheung, P., C.D. Allis, and P. Sassone-Corsi, Signaling to chromatin through histone modifications. Cell, 2000. 103(2): p. 263-71.

9. Berger, S.L., Histone modifications in transcriptional regulation. Current opinion in genetics \& development, 2002. 12(2): p. 142-8.

10. Wagner, E.J. and P.B. Carpenter, Understanding the language of Lys 36 methylation at histone H3. Nature reviews. Molecular cell biology, 2012. 13(2): p. $115-26$.

11. Valinluck, V. and L.C. Sowers, Inflammation-mediated cytosine damage: a mechanistic link between inflammation and the epigenetic alterations in human cancers. Cancer research, 2007. 67(12): p. 5583-6.

12. Jones, P.A. and D. Takai, The role of DNA methylation in mammalian epigenetics. Science, 2001. 293(5532): p. 1068-70. 
13. Bird, A.P., et al., Non-methylated CpG-rich islands at the human alpha-globin locus: implications for evolution of the alpha-globin pseudogene. The EMBO journal, 1987. 6(4): p. 999-1004.

14. Jones, P.A. and S.B. Baylin, The epigenomics of cancer. Cell, 2007. 128(4): p. $683-92$.

15. Robertson, K.D., DNA methylation and human disease. Nature reviews. Genetics, 2005. 6(8): p. 597-610.

16. $\mathrm{Xu}, \mathrm{Y}$., et al., Genome-wide regulation of $5 \mathrm{hmC}, 5 \mathrm{mC}$, and gene expression by Tet1 hydroxylase in mouse embryonic stem cells. Mol Cell, 2011. 42(4): p. 451-64.

17. Cohen, Y., et al., Hypermethylation of $C p G$ island loci of multiple tumor suppressor genes in retinoblastoma. Experimental eye research, 2008. 86(2): p. 201-6.

18. Robertson, K.D. and P.A. Jones, DNA methylation: past, present and future directions. Carcinogenesis, 2000. 21(3): p. 461-7.

19. Cairns, P., et al., Molecular detection of prostate cancer in urine by GSTP1 hypermethylation. Clinical cancer research : an official journal of the American Association for Cancer Research, 2001. 7(9): p. 2727-30.

20. Ginder, G.D., EV(I1)olution of AML DNA methylation. Blood, 2011. 117(1): p. 45.

21. Lugthart, S., et al., Aberrant DNA hypermethylation signature in acute myeloid leukemia directed by EVI1. Blood, 2011. 117(1): p. 234-41.

22. Yegnasubramanian, S., et al., Hypermethylation of $C p G$ islands in primary and metastatic human prostate cancer. Cancer research, 2004. 64(6): p. 1975-86.

23. Clark, S.J. and J. Melki, DNA methylation and gene silencing in cancer: which is the guilty party? Oncogene, 2002. 21(35): p. 5380-7.

24. Vachtenheim, J., I. Horakova, and H. Novotna, Hypomethylation of CCGG sites in the 3' region of H-ras protooncogene is frequent and is associated with $\mathrm{H}$-ras allele loss in non-small cell lung cancer. Cancer research, 1994. 54(5): p. 1145-8.

25. Patra, S.K., Ras regulation of DNA-methylation and cancer. Experimental cell research, 2008. 314(6): p. 1193-201. 
26. Braithwaite, E.K., et al., DNA polymerases beta and lambda mediate overlapping and independent roles in base excision repair in mouse embryonic fibroblasts.

PLoS One, 2010. 5(8): p. e12229.

27. Bestor, T.H., The DNA methyltransferases of mammals. Human molecular genetics, 2000. 9(16): p. 2395-402.

28. Wilson, S.H., et al., Base excision repair and design of small molecule inhibitors of human DNA polymerase beta. Cellular and molecular life sciences : CMLS, 2010. 67(21): p. 3633-47.

29. Zharkov, D.O., Base excision DNA repair. Cellular and molecular life sciences : CMLS, 2008. 65(10): p. 1544-65.

30. De Bont, R. and N. van Larebeke, Endogenous DNA damage in humans: a review of quantitative data. Mutagenesis, 2004. 19(3): p. 169-85.

31. Sweasy, J.B., T. Lang, and D. DiMaio, Is base excision repair a tumor suppressor mechanism? Cell cycle, 2006. 5(3): p. 250-9.

32. Liu, Y., et al., DNA polymerase beta and flap endonuclease 1 enzymatic specificities sustain DNA synthesis for long patch base excision repair. The Journal of biological chemistry, 2005. 280(5): p. 3665-74.

33. Cooke, M.S., et al., Oxidative DNA damage: mechanisms, mutation, and disease. The FASEB journal : official publication of the Federation of American Societies for Experimental Biology, 2003. 17(10): p. 1195-214.

34. Hitchler, M.J. and F.E. Domann, An epigenetic perspective on the free radical theory of development. Free radical biology \& medicine, 2007. 43(7): p. 1023-36.

35. Wang, B., et al., Histone deacetylase inhibition activates transcription factor Nrf2 and protects against cerebral ischemic damage. Free radical biology \& medicine, 2012. 52(5): p. 928-36.

36. Reardon, J.T., et al., In vitro repair of oxidative DNA damage by human nucleotide excision repair system: possible explanation for neurodegeneration in xeroderma pigmentosum patients. Proceedings of the National Academy of Sciences of the United States of America, 1997. 94(17): p. 9463-8.

37. Valinluck, V., et al., Oxidative damage to methyl-CpG sequences inhibits the binding of the methyl-Cp G binding domain (MBD) of methyl-CpG binding protein 2 (MeCP2). Nucleic acids research, 2004. 32(14): p. 4100-8. 
38. Li, Y.Q., et al., Association of Dnmt3a and thymine DNA glycosylase links DNA methylation with base-excision repair. Nucleic acids research, 2007. 35(2): p. 390-400.

39. Boland, M.J. and J.K. Christman, Characterization of Dnmt3b:thymine-DNA glycosylase interaction and stimulation of thymine glycosylase-mediated repair by $D N A$ methyltransferase(s) and RNA. Journal of molecular biology, 2008. 379(3): p. $492-504$.

40. Mortusewicz, O., et al., Recruitment of DNA methyltransferase I to DNA repair sites. Proceedings of the National Academy of Sciences of the United States of America, 2005. 102(25): p. 8905-9.

41. Carey, N., C.J. Marques, and W. Reik, DNA demethylases: a new epigenetic frontier in drug discovery. Drug discovery today, 2011. 16(15-16): p. 683-90.

42. Teperek-Tkacz, M., et al., Epigenetic reprogramming: is deamination key to active DNA demethylation? Reproduction, 2011. 142(5): p. 621-32.

43. Zhu, J.K., Active DNA demethylation mediated by DNA glycosylases. Annual review of genetics, 2009. 43: p. 143-66.

44. Cortellino, S., et al., Thymine DNA glycosylase is essential for active DNA demethylation by linked deamination-base excision repair. Cell, 2011. 146(1): p. 67-79.

45. Ficz, G., et al., Dynamic regulation of 5-hydroxymethylcytosine in mouse ES cells and during differentiation. Nature, 2011. 473(7347): p. 398-402.

46. Guo, J.U., et al., Hydroxylation of 5-methylcytosine by TET1 promotes active DNA demethylation in the adult brain. Cell, 2011. 145(3): p. 423-34.

47. He, Y.F., et al., Tet-mediated formation of 5-carboxylcytosine and its excision by TDG in mammalian DNA. Science, 2011. 333(6047): p. 1303-7.

48. Ito, S., et al., Myrsinoic acid B inhibits the production of hydrogen sulfide by periodontal pathogens in vitro. J Breath Res, 2010. 4(2): p. 026005.

49. Ito, S., et al., Tet proteins can convert 5-methylcytosine to 5-formylcytosine and 5carboxylcytosine. Science, 2011. 333(6047): p. 1300-3.

50. Koh, K.P., et al., Tet1 and Tet2 regulate 5-hydroxymethylcytosine production and cell lineage specification in mouse embryonic stem cells. Cell Stem Cell, 2011. 8(2): p. 200-13. 
51. Pastor, W.A., et al., Genome-wide mapping of 5-hydroxymethylcytosine in embryonic stem cells. Nature, 2011. 473(7347): p. 394-7.

52. Popp, C., et al., Genome-wide erasure of DNA methylation in mouse primordial germ cells is affected by AID deficiency. Nature, 2010. 463(7284): p. 1101-5.

53. Rai, K., et al., DNA demethylation in zebrafish involves the coupling of a deaminase, a glycosylase, and gadd45. Cell, 2008. 135(7): p. 1201-12.

54. Song, C.X., et al., Selective chemical labeling reveals the genome-wide distribution of 5-hydroxymethylcytosine. Nat Biotechnol, 2011. 29(1): p. 68-72.

55. Williams, K., et al., TET1 and hydroxymethylcytosine in transcription and DNA methylation fidelity. Nature, 2011. 473(7347): p. 343-8.

56. Wu, H., et al., Genome-wide analysis of 5-hydroxymethylcytosine distribution reveals its dual function in transcriptional regulation in mouse embryonic stem cells. Genes \& development, 2011. 25(7): p. 679-84.

57. Wu, H., et al., Dual functions of Tet1 in transcriptional regulation in mouse embryonic stem cells. Nature, 2011. 473(7347): p. 389-93.

58. Gehring, M., W. Reik, and S. Henikoff, DNA demethylation by DNA repair. Trends in genetics: TIG, 2009. 25(2): p. 82-90.

59. Morgan, H.D., et al., Activation-induced cytidine deaminase deaminates 5methylcytosine in DNA and is expressed in pluripotent tissues: implications for epigenetic reprogramming. The Journal of biological chemistry, 2004. 279(50): p. 52353-60.

60. Masaoka, A., et al., Mammalian 5-formyluracil-DNA glycosylase. 2. Role of SMUG1 uracil-DNA glycosylase in repair of 5-formyluracil and other oxidized and deaminated base lesions. Biochemistry, 2003. 42(17): p. 5003-12.

61. Bjelland, S., et al., Oxidation of thymine to 5-formyluracil in DNA: mechanisms of formation, structural implications, and base excision by human cell free extracts. Biochemistry, 1995. 34(45): p. 14758-64.

62. Alba, M.M., M.F. Santibanez-Koref, and J.M. Hancock, The comparative genomics of polyglutamine repeats: extreme differences in the codon organization of repeat-encoding regions between mammals and Drosophila. J Mol Evol, 2001. 52(3): p. 249-59. 
63. Liu, Y., et al., Coordination of steps in single-nucleotide base excision repair mediated by apurinic/apyrimidinic endonuclease 1 and DNA polymerase beta. The Journal of biological chemistry, 2007. 282(18): p. 13532-41.

64. Niehrs, C., Active DNA demethylation and DNA repair. Differentiation; research in biological diversity, 2009. 77(1): p. 1-11.

65. Niehrs, C. and A. Schafer, Active DNA demethylation by Gadd45 and DNA repair. Trends in cell biology, 2012. 22(4): p. 220-7.

66. Wolfle, W.T., et al., Human DNA polymerase kappa uses template-primer misalignment as a novel means for extending mispaired termini and for generating single-base deletions. Genes \& development, 2003. 17(17): p. 2191-9.

67. Pardo, B., E. Ma, and S. Marcand, Mismatch tolerance by DNA polymerase Pol4 in the course of nonhomologous end joining in Saccharomyces cerevisiae. Genetics, 2006. 172(4): p. 2689-94.

68. Sassa, A., et al., DNA sequence context effects on the glycosylase activity of human 8-oxoguanine DNA glycosylase. The Journal of biological chemistry, 2012. 287(44): p. 36702-10.

69. Sweasy, J.B., Fidelity mechanisms of DNA polymerase beta. Progress in nucleic acid research and molecular biology, 2003. 73: p. 137-69.

70. Zhang, Y., et al., Highly frequent frameshift DNA synthesis by human DNA polymerase mu. Molecular and cellular biology, 2001. 21(23): p. 7995-8006.

71. Covo, S., L. Blanco, and Z. Livneh, Lesion bypass by human DNA polymerase mu reveals a template-dependent, sequence-independent nucleotidyl transferase activity. The Journal of biological chemistry, 2004. 279(2): p. 859-65.

72. Chou, K.M. and Y.C. Cheng, An exonucleolytic activity of human apurinic/apyrimidinic endonuclease on 3' mispaired DNA. Nature, 2002. 415(6872): p. 655-9. 